\title{
Assessing opportunities and constraints for biofuel development in sub-Saharan Africa
}

Graham von Maltitz

William Stafford

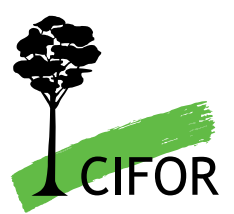





\section{Assessing opportunities and constraints for biofuel development in sub-Saharan Africa}

Graham von Maltitz

William Stafford 
Working Paper 58

(c) 2011 Center for International Forestry Research.

All rights reserved

Von Maltitz, G. and Staffford, W. 2011 Assessing opportunities and constraints for biofuel development in sub-Saharan Africa. Working Paper 58. CIFOR, Bogor, Indonesia

Cover photo by Graham von Maltitz

This paper has been produced with the financial assistance of the European Union, under a project titled, 'Bioenergy, sustainability and trade-offs: Can we avoid deforestation while promoting bioenergy?' The objective of the project is to contribute to sustainable bioenergy development that benefits local people in developing countries, minimises negative impacts on local environments and rural livelihoods, and contributes to global climate change mitigation. The project will achieve this by producing and communicating policy relevant analyses that can inform government, corporate and civil society decision-making related to bioenergy development and its effects on forests and livelihoods. The project is managed by CIFOR and implemented in collaboration with the Council on Scientific and Industrial Research (South Africa), Joanneum Research (Austria), the Universidad Nacional Autónoma de México and the Stockholm Environment Institute. The views expressed herein can in no way be taken to reflect the official opinion of the European Union.

\section{CIFOR}

Jl. CIFOR, Situ Gede

Bogor Barat 16115

Indonesia

$\mathrm{T}+62$ (251) 8622-622

$\mathrm{F}+62(251) 8622-100$

Ecifor@cgiar.org

www.cifor.cgiar.org

Any views expressed in this publication are those of the authors. They do not necessarily represent the views of CIFOR, the authors' institutions or the financial sponsors of this publication. 


\section{Table of contents}

$\begin{array}{ll}\text { Abbreviations } & \text { vi }\end{array}$

$\begin{array}{ll}\text { Abstract } & \text { vii }\end{array}$

1 Introduction $\quad 1$

2 Conceptual and methodological approach 3

2.1 Determining 'desirable outcomes' 3

2.2 Developing a typology of biofuel production schemes 5

$\begin{array}{lll}2.3 \text { Analysing opportunities and constraints } & 6\end{array}$

$\begin{array}{lll}2.4 & \text { Policy options for driving desirable outcomes } & 7\end{array}$

$\begin{array}{ll}2.5 \text { Methodological constraints } & 9\end{array}$

3 What should African countries aim to achieve from biofuels? 10

4 A closer look at four types of biofuel development 16

4.1 Type A: Large-scale liquid biofuel plantations 16

4.2 Type B: Small-scale private farmers and outgrowers to produce feedstock destined
for the national or international liquid fuel blends

\begin{tabular}{ll}
4.3 & Type C: Small-scale local energy plantations \\
\hline
\end{tabular}

4.4 Type D: Large-scale local energy plantations 31

5 Actions for achieving improved models of biofuel development 33

5.1 Increasing the ratio of small-scale to large-scale plantations 33

5.2 Moving from global fuel supply to local fuel security 36

$\begin{array}{ll}5.3 \text { Developing a small-scale farming sector } & 39\end{array}$

6 Large-scale versus small-scale processing facilities $4 \mathbf{4 3}$

6.1 Opportunities from small-scale biofuel processing facilities 43

6.2 Constraints to the establishment of small-scale biofuel processing 43

7 Conclusions $\quad 46$

8 References $r 49$ 


\section{List of tables and figures}

\section{Tables}

$1 \quad$ Links between desirable outcomes from African policy level commitment and biofuel development 4

2 Examples of incentives and disincentives for biofuel development

\section{Figures}

1 Proposed typology of biofuel projects based on scale of operation and intended market

2 These projects provide feedstock from large-scale corporate plantations that is dedicated to national or international liquid transportation fuel blends

3 These projects provide feedstock from micro to small-scale farms that is dedicated to national or international liquid transport fuel blends

4 These projects provide feedstock from micro to small-scale farms that produce biofuels to meet household or local village energy needs

5 These projects are corporate, large-scale projects that provide energy to a related corporation for local use

6 Use of policy interventions to change the ratio of feedstock production from large-scale to smallscale producers

7 Use of policy interventions to stimulate biofuel projects for local energy use rather than sale to the liquid transport fuel markets

8 GJ of usable cooking energy per ha of land used to grow the feedstock based on von Maltitz and Mapako (in prep). The mode value represents likely current scenarios, with the low and high values based on both production and consumption efficiencies.

9 Use of policy to use biofuel to stimulate the development of small- to medium-scale farmers 


\section{Abbreviations}

$\begin{array}{ll}\text { BSI } & \text { Better Sugar Cane Initiative } \\ \text { CIFOR } & \text { Center for International Forestry Research } \\ \text { CO }_{2} & \text { Carbon dioxide } \\ \text { COMPETE } & \text { Competence Platform on Energy Crop and Agroforestry Systems for Arid and } \\ & \text { Semi-arid Ecosystems, Africa } \\ \text { CSIR } & \text { Council for Scientific and Industrial Research (South Africa) } \\ \text { EC } & \text { European Commission } \\ \text { FAO } & \text { Food and Agricultural Organization of the United Nations } \\ \text { FSC } & \text { Forest Stewardship Council } \\ \text { GAIA } & \text { Movement Trust Living Earth Green World Action } \\ \text { GAP } & \text { Good Agricultural Practices } \\ \text { GHG } & \text { Greenhouse gas } \\ \text { GIZ } & \text { Gesellschaft für Internationale Zusammenarbeit } \\ \text { Ha } & \text { Hectare } \\ \text { HCV } & \text { High Conservation Value } \\ \text { HDI } & \text { Human Development Index } \\ \text { LA } & \text { Latin America } \\ \text { MDG } & \text { Millennium Development Goals } \\ \text { OECD } & \text { Organisation for Economic Co-operation and Development } \\ \text { ProBEC } & \text { Programme for Basic Energy and Conservation of GIZ } \\ \text { RED } & \text { Renewable Energy Directive of the European Union } \\ \text { RSB } & \text { Roundtable on Sustainable Biofuels } \\ \text { RSPO } & \text { Roundtable on Sustainable Palm Oil } \\ \text { RTRS } & \text { Roundtable on Responsible Soy } \\ \text { SADC } & \text { Southern Africa Development Community } \\ \text { SAN } & \text { Sustainable Agriculture Network } \\ \text { SEA } & \text { Southeast Asia } \\ \text { SSA } & \text { Sub-Saharan Africa } \\ \text { UNCBD } & \text { United Nations Convention on Biological Diversity } \\ \text { USA } & \text { United States of America } \\ & \end{array}$




\section{Acknowledgements}

We gratefully acknowledge the support received from the Council for Scientific and Industrial Research in South Africa as well as the European Commission. The authors would like to thank Bamikola Amigun, Maxwell Mapako, Annie Sugrue, Pablo Pacheco and George Schoneveld for their valuable comments and contributions to early drafts of this paper. Eric Kemp-Benedict and Laura German provided inspiration during many long debates on policy instruments. In addition the entire project team from the EU-funded project, 'Bioenergy, sustainability and trade-offs: Can we avoid deforestation while promoting bioenergy?' have provided extensive background studies and lively debate that have helped develop the ideas presented in this working paper. 


\section{Introduction}

Until the mid-2000s, biofuel feedstock production was little developed in sub-Saharan Africa (SSA) ${ }^{1}$. Although Malawi and Zimbabwe produced ethanol that was blended with petroleum, this was largely from molasses, a byproduct of the already established sugar industry, and the blended fuel was only used in relatively small domestic markets (von Maltitz and Brent 2009, Chamdimba 2009). Then from 2004 to 2008 , interest in biofuels underwent a huge revival, largely attributed to the movement toward mandatory fuel blends in Europe and other developed nations (von Maltitz et al. 2009). SSA's biofuel production potential was highlighted in several studies, helping to drive interest in Africa for biofuel investment (Smeets et al. 2007, Batidzirai et al. 2006, Johnson and Matsika 2006) and prompting international investors to acquire large tracts of land for feedstock plantations in SSA (Schutter 2009, World Bank 2010, Friis and Reenberg 2010). Simultaneously, the environmental and social sustainability of biofuels came under extensive scientific scrutiny (e.g. The Royal Society 2008, Gallagher 2008), and initiatives emerged to develop guidelines for sustainable production (e.g. the Roundtable on Sustainable Biofuels), as well as market regulations from consumer countries (e.g. EU) and producer countries (e.g. South Africa and Mozambique).

The global recession of 2008/2009 partially dampened the international demand for biofuel land acquisition in Africa and shifted the focus toward acquisition for food production (World Bank 2010). As a consequence, many biofuel development projects were never put into practice (Friis and Reenberg 2010). However, recent increases in oil prices may revive interest in biofuel development, and it is imperative that SSA countries strategically assess the socio-economic implications of biofuel expansion, and develop appropriate policies to ensure that if they engage in biofuel development, they do so in a way

1 We will limit the discussion to sub-Saharan Africa since many aspects of north Africa such as high oil reserves, low rainfall and a generally higher standard of socio-economic development make the north African situation uniquely different from SSA. Extensive biofuel production in north Africa is also unlikely. that optimises national welfare (Haywood et al. 2010). Furthermore, the volatility in oil prices also indicates that SSA countries need to assess the potential of biofuels to improve their national fuel security (SADC 2010).

Many studies highlight the potential pitfalls of biofuel expansion in Africa. For example, the potential social problems due to the poor land tenure security of local communities has received extensive coverage (Cotula et al. 2008 and 2009, German et al. 2010a, Schoneveld et al. 2010, Sulle and Nelson 2009), as have concerns around deforestation and biodiversity loss (von Maltitz et al. 2010) and the low overall development benefits (German et al. 2010a, Schoneveld et al. 2010).

A number of African countries have responded by developing new policy frameworks to deal with this new, large-scale land use option, although only a few countries have as yet completed this process. In addition, the development of sustainability principles, criteria and indicators for biofuel development, and constraints to imports in the EU, have been some key responses to reduce unsustainable practices (Harrison et al. 2010a, Vis et al. 2008). Though the adoption of a market-based certification process is an extremely powerful mechanism to enhance sustainability, it is insufficient to ensure that biofuel development will be conducted in the most beneficial manner within producer countries (Harrison et al. 2010a). This is because biofuel certification is focused on a specific project's implementation, thus neglecting a strategic national view of how biofuel development should be conducted in general. In addition, a national strategic plan for biofuel development should include rigorous, strategic socio-economic and environmental assessments to ascertain if biofuels are an appropriate land use option for the country, and this should be done in an inclusive and transparent manner (Haywood et al. 2010).

Assuming that a country has decided to engage in biofuel development, then a key consideration is to ensure that optimal benefits are achieved. 
This working paper investigates some options to increase positive benefits flowing from biofuels expansion. However, in order to understand how to increase benefits, it is first important to understand what SSA countries would wish to achieve from biofuel development.

This working paper's main objectives are: 1) to understand what desirable outcomes SSA countries should be aiming to achieve from biofuel expansion; 2) to analyse the opportunities and constraints for enhanced local and national ${ }^{2}$ benefits flowing from different biofuel production models; and, 3 ) to consider policy interventions to enhance local and national benefits.

This working paper focuses predominantly on biofuel feedstock production, since this may deliver widespread rural development benefits if it is financially viable, and at the same time, potentially result in widespread social and environmental impacts. The land footprint and job opportunities from feedstock production are many orders of magnitude greater than those of the processing plants. Thus, incorrect decisions relating to feedstock production could have huge and potentially irreversible social and environmental impacts.

We adopt an approach that differs substantially from the most common approach of using sustainability principles and criteria for assessing biofuel projects. ${ }^{3}$ Here, we attempt to identify opportunities for enhanced overall national benefits from biofuel expansion, and as such this working paper does not focus on the opportunities and constraints of a specific project. The key national benefit envisaged from biofuel expansion is enhanced rural development. However, other benefits such as national economic benefits and fuel security are also acknowledged. The links between biofuel expansion and deforestation receive specific attention, and the opportunity to use biofuels as a mechanism to reduce

2 'National' is used here to mean benefits to the nation in general as opposed to benefits to the biofuel company. Most of these national benefits should be benefits to local communities. 3 We disregarded the approach of looking at actual developments based on existing criteria and indicators, since these focus on specific projects rather than adopting a broader perspective. The sustainability standard set minimum criteria rather than suggesting optimum approaches - in other words, the standard sought to prevent bad practice rather than identify best practice. deforestation is explored. The Greenhouse Gas (GHG) emissions from direct and indirect land use changes needs to be balanced with the benefits of biofuels substituting petroleum-based fuels.

All recommendations in this working paper are generic in nature; site- and situation-specific assessments must be undertaken when dealing with specific projects.

The working paper consists of 7 sections including this introduction. The second section describes the methodological approach adopted. The third provides a justified list of 17 desirable outcomes that African nations should be seeking from biofuel expansion; these are clustered into 4 groups: livelihoods and development, energy poverty and security, attracting appropriate investment, and sustainable land use. The fourth section analyses the opportunities and constraints for biofuel development based on four production models, and the following section considers the option of moving the ratio of biofuel feedstock between different models. The sixth section briefly considers the processing aspects of biofuel production and the potentially inherent opportunities for enhancing national benefits. The final section provides some overall conclusions. 


\section{Conceptual and methodological approach}

The approach adopted in this study consists primarily of 3 steps. The first is to determine the desirable outcomes from biofuel development in 4 main themes (livelihoods and development; energy poverty and security; attracting appropriate investment; and sustainable land use). The second is to explore the main production and business models that are being implemented to produce biofuel feedstocks by linking scales of production and intended markets. The third is to adopt criteria for assessing the opportunities and constraints of these different production and business models, to understand how they can achieve the desirable outcomes and what policy approaches could be adopted to make that possible. Below we discuss in more detail the conceptual underpinnings and methodological challenges for adopting this approach.

\subsection{Determining 'desirable outcomes'}

To determine what SSA countries may wish to achieve from biofuel programmes (what we term here as desirable outcomes), a synthesis of issues was derived from a number of Africa-wide, regional or national policy engagements. In addition, African country commitments to United Nations conventions were considered. Sources include the Southern Africa Development Community (SADC) biofuel sustainability objectives (SADC 2010); the CSIR/ CIFOR/SADC assessment of objectives, criteria and policy mechanisms ${ }^{4}$; the African Roundtable for Sustainable Consumption and Production (ARSCP); and, the first High-Level Biofuels Seminar in Africa jointly organised by the African Union, the Government of Brazil and the United Nations Industrial Development Organisation (IISD/UNIDO 2007). Outcomes from the COMPETE ${ }^{5}$ project

4 As a component of the EC-funded project 'Bioenergy, sustainability and trade-offs: Can we avoid deforestation while promoting biofuels, an ongoing process of policy engagement has included workshops on the criteria and indicators of outcomes that countries desire from biofuel projects.

5 Competence Platform on Energy Crop and Agroforestry Systems for Arid and Semi-arid Ecosystems- Africa (COMPETE) was an EU project funded through the 6th Framework

Programme: http://www.compete-bioafrica.net/. The report by Janssen and Rutz (2009) captures the policy outcomes from the various policy dialogues. are considered, including the COMPETE Arusha declaration, COMPETE Lusaka recommendations, COMPETE recommendations on financing and COMPETE policy recommendations from Brussels (Janssen and Rutz 2009). Furthermore, individual national policy objectives, as summarised in von Maltitz et al. (2010) were taken into consideration. In addition, since all African countries are signatories to the Millennium Development Goals (MDG), these objectives can be seen as important overarching African development goals. Most African countries are also signatories to the global environmental conventions on Biodiversity, Climate Change and Desertification, and the conventions' objectives are regarded as representing African commitments.

Several international initiatives to define sustainable criteria for biofuel development have also emerged, in addition to Africa-based initiatives. Probably the most important has been the Roundtable on Sustainable Biofuels (RSB). Though the RSB standard is globally orientated, and is in part driven by European certification needs, extensive African consultation was undertaken in its development. Other initiatives include the Roundtable on Sustainable Palm Oil (RSPO), the Roundtable on Responsible Soy (RTRS), the Better Sugar Cane Initiative (BSI) and the Sustainable Agriculture Network (SAN). Though not focused specifically on biofuels, a number of agricultural and forestry standards have been developed, including Good Agricultural Practices (GAP), Forest Stewardship Council (FSC) and Fairtrade (Harrison et al. 2010a, Cushion et al. 2010), as well as national guidelines on how agriculture, knowledge, science and technology can ensure future food production and sustainable agricultural systems (IAASTD 2008a).

Desirable outcomes from biofuels are determined here. These 17 desirable outcomes have been clustered into 4 themes: livelihoods and development; energy poverty and security; attracting appropriate investment; and, sustainable land use. The way these desirable outcomes link to the resolutions from various Africa-wide or region-wide biofuel policy 
Table 1a. Links between desirable outcomes from African policy level commitment and biofuel development

\begin{tabular}{llllllll}
\hline Impact areas & $\begin{array}{l}\text { CSIR/ } \\
\text { SADC }\end{array}$ & $\begin{array}{l}\text { SADC } \\
\text { sustain- } \\
\text { ability } \\
\text { objectives }\end{array}$ & $\begin{array}{l}\text { IISD/ } \\
\text { UNIDO } \\
\text { High-level } \\
\text { biofuel } \\
\text { seminar }\end{array}$ & $\begin{array}{l}\text { COMPETE } \\
\text { Arusha } \\
\text { declaration }\end{array}$ & $\begin{array}{l}\text { COMPETE } \\
\text { Lusaka } \\
\text { recommend- } \\
\text { ation }\end{array}$ & $\begin{array}{l}\text { COMPETE } \\
\text { Financing } \\
\text { recommend- } \\
\text { ations }\end{array}$ & $\begin{array}{l}\text { COMPETE } \\
\text { Brussels }\end{array}$ \\
\hline $\begin{array}{l}\text { Livelihood and } \\
\text { development } \\
\text { impacts }\end{array}$ & 12 & $\begin{array}{l}12 \mathrm{i} 3 \mathrm{i} 4 \mathrm{i} \\
56 \mathrm{i}\end{array}$ & $12 \mathrm{i} 6 \mathrm{i}$ & $12456 \mathrm{i}$ & 12 & $1 \mathrm{i}$ & 1 (rest \\
implied)
\end{tabular}

Notes: Numbers correspond to the sustainability objective in Table 1b. An ' $\mathrm{i}$ ' after the number indicates it is inferred, whereas a number on its own indicates that the objective is clearly articulated in the document considered.

Table 1b. Sustainability objectives
1. Rural development
2. Improved local rural livelihoods
3. Sensitive to gender equity issues
4. Large-scale projects to benefit rather than displace existing local livelihoods
5. Food security needs to be protected
6. Greater resilience of rural livelihoods and national economies
7. Increased national fuel security
8. Increased local access to energy
9. Attract foreign investment that is appropriate and conditional on achieving policy objectives
10. Value-added products rather than raw biofuel feedstock should be exported
11. Maximise the retention of financial benefits within the country
12. A net national economic benefit
13. Appropriate and sustainable land use
14. Linked to modernisation of agricultural practices
15. Environmentally appropriate
16. No net increase in deforestation
17. Long-term sustainability

initiatives is illustrated in Table 1. These positive outcomes are not designed to be a set of principles, as used for instance by the RSB as the basis for certification, but rather as a guide to desirable outcomes that policy interventions should aim to achieve. In essence, criteria as in the RSB are designed to prevent bad practice, whereas here the conditions that will enhance benefit flows are considered and highlighted. These desirable outcomes therefore in no way replace the sustainably criteria used in certification, but should be used in conjunction to help achieve national objectives.
Note that these desirable outcomes are generic and that for any specific country or project, locally specific considerations are needed. Also note that although many desirable outcomes are complimentary, tradeoffs between achieving some outcomes are also probable and therefore locality-specific weighting would be needed to determine which outcomes are the most desirable; this is beyond the scope of this paper. 


\subsection{Developing a typology of biofuel production schemes}

Biofuel projects respond to goals for local fuel provision or as a cash crop to be sold for liquid biofuel production for national or international markets (Haywood et al. 2008, von Maltitz et al. 2009). In addition, biofuel feedstock production tends to occur either on small-scale family farms (subsistence ${ }^{6}$ or small-scale commercial), or on large corporate estates. In a few examples, medium-size farms can be found, but these are the exception and are limited mostly to South Africa. Figure 1 provides a 2-way typology of projects. The $\mathrm{X}$ axis differentiates projects based on the size of the feedstock-producing farm. Although farm size is theoretically a continuum, in practice farms tend to be either very small (only a few ha) or extremely large (thousands of ha). The $Y$ axis represents the intended final purpose (or market) for which the biofuel is being grown. Although markets can range from local use to national use to international export, in practice a dichotomy of markets/uses exists. Based on the above, 4 unique types of feedstock production models are identified, ranging from $A$ to $D$ in Figure 1. This typology is based on Haywood et al. (2008) and von Maltitz et al. (2009).

The large-scale liquid biofuel blend plantations (A) are the typical model of direct foreign investment. The plantations have the single function of producing feedstocks for biofuel devoted to national or international biofuel blending targets. These plantations are primarily mono-crops and are well managed using modern farming practices. The plantation typically has corporate ownership, sometimes with capital raised on foreign stock exchanges or through private investment. A manager manages the plantation and casual or full-time employees are recruited as waged labour to undertake tasks such as planting, maintenance and harvesting. In many African countries the land is in communal

\footnotetext{
6 The key difference between a subsistence and small-scale farmer as we use the terms here is that subsistence farmers grow crops mainly for home consumption (with a small amount of farmland dedicated to cash crops), whereas the small-scale commercial farmer predominantly sells his/her produce as a cash crop. As a general guideline, subsistence farmers are farming only a few ha (less than 10 , but typically only $1-3$ ha). Smallscale farms could range from 5 to 100 ha with medium-scale farms from 100 to 1000 ha. Note these sizes are for guidance only, as the nature of the farming also depends on the land's agronomic potential.
}

or government tenure and the biofuels company leases land from the state or community. This type of farming is sometimes referred to as leasehold farming. In countries with freehold title, this type of estate could be established on private freehold land. This has been observed in the South African sugar industry.

The small-scale liquid biofuel blend farms (B) model corresponds to small-scale farmers producing biofuels either on their existing farms or on dedicated new small farms established specifically for feedstock production. To the farmer, biofuel feedstock production is simply a cash crop. The farmer sells the crop for cash income to mills, processing plants or intermediaries (who collect for the mills/processing plants). The feedstock is grown specifically to meet national or international biofuel blending targets. These small-grower schemes are often, but not always, linked to large-scale estates, and typically referred to as outgrowers. In many instances these farmers enter into long- or short-term contracts with the mill which is sometimes referred to as 'contract farming.' Household labour is the main labour on these farms, though additional external labour may be hired for labour intensive tasks such as land preparation and harvesting. Labour intensive operations are used, or in some instances the large-scale estate, mill or independent service providers provide mechanisation for processes such as ploughing, harvesting and transportation. The mill may provide extensive support for the farmers, including financial support for inputs which are typically deducted from final payments when the feedstock is delivered; inputs such as fertiliser and pesticides; access to machinery; and technical support. In return, the farmer in most cases enters into an annual or long-term contract with the mill.

Small-scale local energy farms (C) are typically affiliated with projects that supply fuel to generators for local electrical power needs. In some instances local power utilities have been set up to provide the local village with power, as is the case with the Mali Folke Centre project in Mali (a local initiative supported by the FACT Foundation). Multifunctional platforms that produce electricity, milling and pumping services (these are common in Tanzania) can be powered by locally produced pure plant oil or processed biofuel (UNDESA 2007). The biofuel could also provide fuel for household use such as 


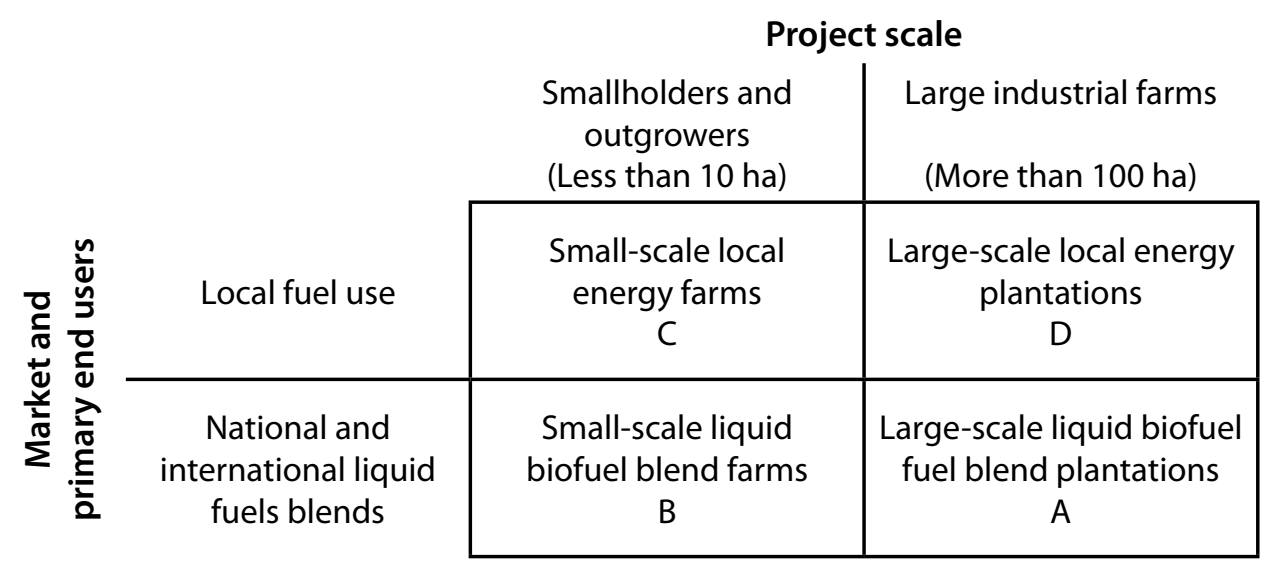

Figure 1. Proposed typology of biofuel projects based on scale of operation and intended market

cooking or lighting, but this is more of a challenge as existing technology to use pure plant oil directly in the home is cost-prohibitive for most poor households. The greatest successes have been when the pure plant oil is used directly in diesel generators to make electricity for rural homes. The farmer may either sell feedstock as a cash crop to the local power utility, or may be in a collective where the provision of feedstock offsets community power costs. Projects using microdistilleries to produce ethanol gel for local use have been tried in Ethiopia and Brazil (Gaia Movement Trust Living Earth Green World Action (GAIA)).

The large-scale local energy plantations $(D)$ are a relatively unusual model. It involves growing biofuel feedstock using waged labour, to meet the energy requirements of the corporation itself, which are frequently mines or large commercial farms.. The biofuel may be used to power generators, or liquid transport fuel needs. The key differentiation between this and (A) is the nature of the market and the underlying reasons for growing the feedstock. The feedstock is grown to provide energy to the core operation as a cost saving measure, and not to sell as a crop or energy product for commercial reasons.

The above framework provides a useful and powerful framework for better understanding the nature and criteria for sustainability of different types of biofuel projects with significant policy implications.

7 GAIA is an NGO network engaged in sustainability issues in many developing countries. http://www.gaia-movement.org/.

\subsection{Analysing opportunities and constraints}

In order to document the analysis of the opportunities and constraints associated with developing each of the 4 different models identified above, project data documented from numerous biofuel case studies was used, supplemented by an extensive review of available literature. The case studies include those summarised in German et al. (2010b) and cases commissioned by the GIZ-funded Program for Basic Energy and Conservation in Southern Africa (ProBEC) project ${ }^{8}$; a number of projects linked to the EC-funded Re-impact Project were visited personally. In addition, abundant gray literature provides extensive case studies in Africa. This working paper also uses information derived through the process of developing scenario models with the SADC biofuels secretariat and member states' biofuel representatives ${ }^{9}$. This process is attempting to model linkages between policy actions and their impacts on biofuel development and entails extensive deliberation with national biofuel representatives on the linkages between biofuel sustainability and available policy options.

The working paper's focus is not on assessing the opportunities and constraints related to establishing biofuel projects but rather on the opportunities for increasing the benefits from biofuel production for the economy and society as a whole, and the

8 These case studies are available at www.probec.org.

9 The EC project 'Bioenergy, sustainability and trade-offs: Can we avoid deforestation while promoting biofuels' has undertaken a process of policy engagement with SADC biofuel policy leaders which includes creating a national level investment model (KempBenedict 2011) and ongoing work on a local-level model. 
constraints that operate as barriers to achieve such goals. For the purpose of analysis these national economic and societal benefits are taken to be the desirable outcomes as identified in section 3. As such, what are sought are policy options that can shift practice in the biofuel sector to enhance the desirable outcomes.

Each of the 4 project models was assessed as to how it can contribute to achieving the desirable outcomes. In doing this analysis, a number of factors were identified as criteria for identifying likely impacts and the nature of the impacts. These were: governance and institutional conditions; access to land and land-based products and how this would be altered as a consequence of biofuel feedstock production; available technologies; impacts of the model on market access; relative bargaining power of different role-players and members of the local community; and financial considerations. A 3-step process was employed. Firstly, the model was assessed in terms of the potential opportunities that it presented to the SSA country. Secondly, constraints limiting the production model's introduction were considered, and, finally, the positive and negative impacts that might be experienced from this model of project implementation were identified.

\subsection{Policy options for driving desirable outcomes}

Two key questions underpin the analysis in this section. The first question was: what interventions can be put in place to ensure that national benefits are being achieved through this model? Once potential policy interventions were identified, the second question was: what type of intervention was most likely to drive investor behaviour in a way that would help the biofuel project meet the national desirable outcomes? In addition to enhancing opportunities from within individual production models, the question was also asked, whether greater benefit could be achieved by shifting the focus to a different production model.

There are 2 alternatives to driving behavioural change in the way the biofuel sector develops and functions. The first is to use regulatory instruments included in policies, and legislation, which translate to incentives

\section{Table 2. Examples of incentives and disincentives for biofuel development}

\begin{tabular}{|c|c|}
\hline Measures & Type of policy instrument \\
\hline \multirow[t]{8}{*}{ Incentives } & $\begin{array}{l}\text { - Mandated blending targets create a national market for biofuels and forces petroleum } \\
\text { companies to source biofuels, hence driving investment in the biofuel sector }\end{array}$ \\
\hline & $\begin{array}{l}\text { - Development of free trade zones where processing facilities can be located encourage } \\
\text { exports }\end{array}$ \\
\hline & - High importation tax on imported fossil fuels limit imports \\
\hline & $\begin{array}{l}\text { - Direct financial assistance in setting up biofuel projects, low interest loans, and co- } \\
\text { investments from the state }\end{array}$ \\
\hline & - Indirect assistance through maintaining extension services \\
\hline & - Funding of research and development \\
\hline & - Tax rebates and preferential purchase agreements \\
\hline & - Investor support services (e.g. in acquiring land) \\
\hline \multirow[t]{8}{*}{ Disincentives } & - Regulations banning activities such as using food crops as biofuel feedstock \\
\hline & - Restrictions on international capital flows \\
\hline & - Adoption of production standards \\
\hline & $\begin{array}{l}\text { Export tariffs on biofuel or feedstock that taxes feedstock export more heavily than } \\
\text { processed biofuel will stimulate local processing }\end{array}$ \\
\hline & - Conditions on foreign ownership \\
\hline & $\begin{array}{l}\text { - Land-use zoning that restricts biofuels to areas not considered critical for other uses, such } \\
\text { as conservation and food production }\end{array}$ \\
\hline & - Business linkage requirements \\
\hline & - Technology transfer requirements \\
\hline
\end{tabular}


and disincentives (carrots and sticks). An alternative option is 'market-based approaches', where the market places pressure on the producers to meet certain minimum standards throughout the production process through the use of certification. Both these approaches have advantages and disadvantages and it is likely that a mixed set of approaches will be applied. The appropriate intervention is situation-dependent, and in most cases a number of simultaneous incentives and disincentives are needed to give the correct balance of outcomes (Harrison et al. 2010a).

\subsubsection{Regulations affecting biofuel production}

The regulatory instruments are normally driven from the national or subnational level, though there are also a number of international processes that may also have an effect. These instruments embrace an array of state legislation covering issues as diverse as employment policy, health and safety policy, environmental policy, trade and investment policy, agricultural policy and energy policy. Specific policy to incentivise or regulate biofuel development often builds on existing broader policy frameworks.

These policy interventions, both incentives and disincentives, are specific, focused policies to change biofuel investment behaviour. In addition generic aspects of the policy environment must also be considered.

For example, at a macroeconomic level, experiences from countries already advanced in renewable energy and biofuel development has shown that good policies have some common characteristics which include: policies that are predictable and consistent over time, civil society buy-in and support, clear niche for small and medium entrepreneurs' benefits, policy coherence, private and public investment, transparent governance, and political will to implement these policies (Chamdimba 2009). Another aspect is the current land tenure regimes in most SSA countries, which constrain biofuel production and can be an opportunity to exploit current land users. Tenure reform or the strengthening of informal tenure regulations could have significant impacts on development (Cotula et al. 2008 and 2009, German et al. 2010a, Schoneveld et al. 2010, Sulle and Nelson 2009, Vermeulen and Cotula 2010).

\subsubsection{Market-based mechanisms}

Market-based mechanisms have developed in the agricultural and forestry sector to ensure that environmentally and socially sound practices are applied throughout the production chain (Cashore et al. 2005, Mayers et al. 2001). In these cases, certified products get wider market exposure and/or a price premium in the market (Mayers et al. 2001). In the case of biofuels, there is potentially an even stronger market force (Woods and Diaz-Chavez 2007, Zarrilli and Burnett 2008, Vis et al. 2008), since much of the current African biofuel is destined for European markets that have been created though the EU RED directive (EC 2009). European markets will only be able to use biofuel to contribute to their emission reduction targets if the biofuel is certified.

Market-based mechanisms rely on certifying the entire biofuel production chain. The responsibility for compliance is placed on companies that produce feedstock and manufacture fuel: They must prove compliance with the minimum certification requirements. A network of independent auditors certifies the compliance which takes the burden of monitoring away from government and puts the responsibility and costs on the industry. A number of initiatives have started developing criteria and indicators for biofuel certification and these have been well summarised in the literature (e.g. Harrison et al. 2010a, Vis et al. 2008, Woods and Diaz-Chavez 2007). The Roundtable on Sustainable Biofuels covers biofuels in general. Crop-specific roundtables for sugar, soy, and palm oil have been, or are currently also under development (Vis et al. 2008).

The key constraints for market-based mechanisms are that the biofuel must be going to a certified market for the mechanisms to have an impact. If large markets exist for uncertified biofuels, then the market-based mechanisms will have limited impact. There are many situations where desirable biofuel outcomes might not be achieved through certification mechanisms, but will rather require financial or legislative incentives (see Harrison et al. 2010a). 


\subsection{Methodological constraints}

With the notable exception of Malawi and Zimbabwe, almost all biofuel development in SSA is relatively recent with most projects still in their planning or early establishment phase (von Maltitz et al. 2009). This means that the projects are not yet fully operational and thus it is difficult to accurately assess the socio-economic and environmental consequences that will occur in the long term. However, there is an established food industry for many of the proposed biofuel feedstocks (e.g. sugarcane and oil palm) so that it is possible to draw on this to understand the dynamics of biofuel feedstock production. Although the industry dynamics for biofuels do differ from food markets, biofuel consumption mandates and high costs of biofuels vis-a-vis fossil fuels, will in the medium term cause biofuel prices to be strongly correlated with the price of its feedstocks. Suggested strategies for improving biofuel benefits are based on current understanding of the biofuel industry based on currently available data, but since actual case studies to assess the impacts are in most instances not available, it is not possible to fully understand possible impacts and many unintended consequences.

In addition, the most common biofuel projects in Africa (by number and area) involve the cultivation of the shrub-like plant jatropha (Jatropha curcas L.)
(Gexsi 2008, von Maltitz et al. draft). These projects, however, are the most difficult to assess since to date there are very few jatropha projects that can be truly considered as mature and operational (van Eijck et al. 2010). In SSA it is only within the last year or two that any commercial projects have started to produce oil from their jatropha plantations, and the volume has been low (van Eijck et al. 2010). Furthermore, a few community projects have promoted jatropha use for household oil and soap-making (Sulle and Nelson 2009). jatropha is an undomesticated (wild) crop with huge genetic variability (Henning 2006) and it is therefore a largely untested crop, especially in plantation conditions. Since most plantations are newly established, and mature yields will only be reached after 5-7 years, it is impossible to ascertain what the mature long-term yields will be from plantations, though may well be less than originally envisaged (van Eijck et al. 2010). In addition the true management requirements of jatropha cultivation and the related costs are also still poorly understood (Boreman et al. in press). We expect that many jatropha plantations are likely to produce far less oil than was originally predicted (van Eijck et al. 2010, GAIA 2010) and therefore the sustainability (socially, environmental and economically) may not be as originally envisaged. 


\section{What should African countries aim to achieve from biofuels?}

The SSA region has a unique set of socio-economic and environmental conditions. It is one of the poorest and least developed areas in the world (UNESC 2007, IFAD 2011) and despite relatively good agronomic conditions over large sections of SSA, the level of food insecurity remains high and rural poverty is rife (World Bank 2010). Based on a perception of large tracts of available land coupled with available labour and good agronomic conditions, a number of studies have suggested that Africa has high biofuel feedstock production potential (Smeets et al. 2007, Batidzirai et al. 2006, Johnson and Matsika 2006, Watson 2010). Africa is a vast continent and from a global perspective its population density is low which suggests that land is still a relatively abundant resource. However, land tenure in Africa is complex, and little of Africa's land can be considered as truly unused (Vermeulen and Cotula 2010). Excluding the conservation areas, most other areas are being used in some way. Large sections are used for cattle grazing coupled with harvesting non-timber forest products (Shackleton and Gumbo 2010, Shackleton et al. 2010). In addition, small-scale agriculture; sometimes using permanent fields, but often using long-term rotation practices in a centuries-old and sustainable manner, is practised throughout the areas with sufficient rainfall to sustain cropping (i.e. the same regions that could potentially be used for growing non-irrigated biofuel crops) (Campbell 1996).

Development and especially rural development remains a huge challenge for Africa (IFAD 2011). Biofuel has been advocated as a potential catalyst to stimulate African development (Diaz-Chavez 2010), and in many ways it would seem well suited to this challenge. Biofuel feedstock production is a land-intensive and potentially a labour-intensive process, factors that would seem to make it well suited to the African situation. In addition, investors are eager to invest in biofuel production in a period when investment in food-based agriculture has been stagnating in Africa (UNESC 2007). Most African countries are eager to attract foreign investment as they do not have the financial resources to initiate development without it. Mandatory blending of biofuel into petroleum in developed countries creates a potentially more lucrative market for biofuels, though the size of this market will be limited to the total volumes of biofuel needed beyond what developed countries can produce domestically. Further, there seems to be a large market for biofuel if it can be produced at a price competitive with petroleum fuels, however the globally available land for biofuel production is unlikely to be sufficient to saturate this market (Lotze-Campen et al. 2009). Despite these seemingly positive benefits of biofuel for Africa, critics have raised numerous concerns about the suitability of biofuels in general, and large-scale corporate plantations in particular, as appropriate development options for Africa. These concerns are based upon issues of land tenure and the displacement of indigenous communities (Cotula et al. 2008, Gordon-Maclean et al. 2008, Schoenveld et al 2010, Sulle and Nelson 2009, Matavel 2009, Vermeulen and Goad 2006), food security (Bailey 2008, Pimentel et al. 2010), low levels of actual livelihood benefits achieved (German et al. 2010a), financial viability (Borman et al. in press), environmental impacts (von Maltitz et al. 2010) and other social, economic and environmental constraints.

\section{Biofuel development must drive rural development}

Biofuel as a driver for rural development is a strong message coming through from national policies and regional policy forums (Domac et al. 2005, Janssen and Rutz 2009, Harrison et al. 2010a) and would be in line with the first Millennium Development Goal (MDG). The need for rural development in Africa is an urgent goal since $76 \%$ of the population is living on less than US $\$ 2$ a day with $53 \%$ in poverty or extreme 
poverty (under US $\$ 1.25$ per day). Of those in extreme poverty, $75 \%$ are rural (IFAD 2011). In contrast to all other regions globally, rural poverty in sub-Saharan Africa has increased by $10 \%$ from 1988 to 2008 (IFAD 2011). In this context, biofuel production could potentially have an overall national developmental impact by reducing foreign exchange expenditure and increasing exports, as well as attracting investments to the agricultural sector that could translate into jobs and income for small-scale farmers in rural areas (Diaz-Chavez 2010, Vermeulen et al. 2009). For biofuel development to increase its contribution to rural development, it should be accompanied by an appropriate policy and institutional environment to ensure that the benefits flow to the rural populations instead of increasing economic inequities and deepening rural poverty.

Despite the majority of Africa's population being rural (64\%), and the important contribution of agriculture to national economies, the national expenditure on rural development throughout Africa remains disproportionally low. International aid and investment in the agricultural sector is low and has been declining (Rosegrant et al. 2005,2008, UNESC 2007). Biofuel development could potentially provide a stimulus for reversing such a trend, and if countries are going to undertake biofuel expansion, optimising the leverage provided by biofuels for rural development should be a key priority. Local ownership of the biofuel initiatives by local farmers and community members is a key aspect to sustainable rural development (Vermeulen et al. 2009). This is due to the fact that local ownership ensures that the facility is based to some extent on local resources and needs, and much of the revenue generated remains in the local economy (WoldeGeorgis and Glantz 2009).

\section{Biofuel development must lead to improvement of local rural livelihoods}

Improving the livelihoods of people living in areas targeted for biofuel expansion should take precedence over creating new livelihood opportunities for people foreign to the area, such as migratory labour. This desirable outcome is aligned with 1) above, but emphasises that biofuel development affects individuals and therefore, in addition to total rural development impacts, it is also important to consider who the winners and losers may be in the process. In most cases biofuel expansion tends to occur through large-scale operations leading to displacement of land-use activities that previously provided the basis of livelihoods for rural people, thereby leading also to the displacement of people (Cotula et al. 2008 and 2009, Sulle and Nelson 2009, German et al. 2010a). Although new livelihood opportunities are generated, these may benefit different people from those affected by the biofuels expansion (Cotula 2011, Graham et al. 2010, Nhantumbo and Salomão 2010). If the total rural livelihood options after introducing the biofuel project are less than before the project then the net effect might be to deepen local poverty, especially amongst vulnerable groups such as women and children (Bailey 2008, van Eijck et al. 2010, WoldeGeorgis and Glantz 2009).

Energy poverty (i.e. the inability to access modern energy sources) as well as financial poverty should be considered when considering the developmental impacts of biofuels. There is a well-established link between energy poverty and financial poverty, with some evidence that alleviating energy poverty can aid in overall poverty reduction (Karekezi and Majoro 2002, UNEP 2005).

\section{Biofuel development must be sensitive to gender equity issues}

This premise is based on the fact that women in most developing countries are responsible for securing energy (e.g. fetching firewood for cooking and heating) and water for their households and doing most of the work in the field. There is, therefore, the potential that biofuels could assist in liberating women from these toilsome burdens (Singh and Sooch 2004) and empowering them, by making fuels more accessible and affordable whilst freeing more time for other activities. However, establishing largescale biofuel feedstock plantations and/or small-scale outgrower projects could have different impacts on men and women. Men and women within the same household as well as male- and female-headed households could face different risks, particularly in their access to and control of land and other productive assets, access to the profits of the biofuel endeavours, their level of participation in decisionmaking and socio-economic activities, employment opportunities and conditions, and their food security. 
These gender and biofuels issues are explored in detail by Karlsson and Banda (2009).

\section{Where large-scale projects are envisaged, these need to benefit rather than displace existing local livelihoods}

Biofuel expansion is largely being carried out through large-scale projects, and in many instances this may be a prerequisite for establishing a viable biofuels industry as investors may require the security of supply guaranteed by large-scale plantations before being prepared to invest. This is especially true where bulk feedstock such as sugar and palm oil are coupled with capital investments in processing plants. Managing the potentially negative social impacts from large-scale plantations, as well as maximising positive spinoffs from the plantations, may mitigate negative impacts. The coupling of large-scale plantations with outgrower production is one potential way to increase local ownership and benefit flows (Diaz-Chavez 2010). In addition, policies can ensure that large-scale investments are conducted in a socially responsible manner (Harrison et al. 2010).

\section{Food security needs to be protected}

The necessity to protect food security when embarking on biofuel programmes is an important consideration for SSA countries and a component of many biofuel strategies and policies. Much of Africa is food insecure or only marginally food-secure despite many areas of good agricultural potential (Eswaran et al. 1997). Globally, food access per capita has increased by $25 \%$ since 1960, whereas for Africa there has been a $10 \%$ decline. Ironically one of the most food insecure groups in SSA is small-scale farmers, who account for $50 \%$ of the food-insecure (Heidhues et al. 2004). In some countries in Africa, concerns surrounding food security have resulted in governments actively cautioning against the development of bioenergy. In Tanzania, for instance, as a result of mounting pressure from farmers and environmental groups, the Government suspended all bioenergy investments and halted land for bioenergy development (Browne 2009). Similarly, the South Africa biofuel strategy excludes maize from ethanol production. The links between food security and biofuel expansion are, however, complex and poorly understood in the African context, with the possibility of synergistic relationships between biofuel expansion and food security (Rossi and Lambrou 2009, Cotula et al. 2008).

\section{Biofuel development should lead to greater resilience of rural livelihoods and national economies}

A large number of externalities such as climate change, global fuel prices and the state of the global economy make local individuals and national economies vulnerable. An important consideration when embarking on biofuel is whether it will reduce or increase the resilience ${ }^{10}$ of the farmers' livelihood strategies. If farmers are moving from a diversified farming system to a monocrop of biofuels, then this could increase vulnerability, but if they include fuel crops within a diverse system they may reduce their vulnerability by opening up new markets and reducing the risk of total crop failure in any given year. At a local scale, including biofuels in the crop mix may increase the resilience of farmers' livelihood strategies (Cortez et al. 2010).

\section{Biofuel development must lead to increased national fuel security}

Energy security is a key driver for biofuel expansion in most SSA national states, and is expressed in all reviewed biofuel policies (von Maltitz et al. 2010). Only 8 SSA countries have identified and exploited fossil fuel reserves, with Nigeria and Angola combined producing $74 \%$ of the region's continental total fossil fuel (BP Statistical Review 2010). Given the trend toward high and volatile fossil fuel prices, all African states are keen to maintain local fuel security. Yet, a trend in many early investment proposals for African biofuel projects was investors seeking land to produce biofuel for the EU market instead of trying to fulfil the energy security goals of the producer countries (Banse et al. 2008, Mohammed 2007). African countries have started to respond to biofuels' development, with a growing trend in policy to first meeting national biofuel targets before allowing exports (Amigun et al. 2011).

10 Resilience can be considered as the ability of a system to absorb shocks and perturbations and hence make it less vulnerable to external stresses (Walker et al. 2004). 


\section{Biofuel development must lead to increased local access to energy}

SSA countries have a high dependency on traditional biofuels, with the rural areas in many countries almost totally dependent on traditional biomass energy (fuelwood or charcoal). In many cases, even urban areas have a high dependency on traditional energy, typically charcoal (Arnold et al. 2003, World Bank 2009, Zulu 2010). Although not strongly articulated in many national biofuel policies - which in many instances are aimed specifically at liquid fuels - local energy provision is a key element of policy in Mali and Ghana, and is echoed in the COMPETE Arusha declaration (Rainer and Rutz 2009). There is substantial support from African leaders and academics that biofuel should help facilitate a local transition from traditional to modern fuel use (UNDESA 2007). Overall, poverty and energy poverty are closely linked, with numerous studies suggesting that better access to modern energy sources is a key mechanism for assisting the poor to escape from poverty (Singh and Sooch, 2004, World Bank 2009, UNDESA 2007, Miranda et al. 2010).

\section{Highly desirable foreign investment needs to be appropriate and conditional on achieving policy objectives}

Biofuel expansion in most SSA countries is unlikely without foreign investment to stimulate the process, due to inadequate national capital investment and low levels of technical capacity (Amigun et al. 2008). Most African countries are actively seeking foreign investment, with a number including Mozambique and Tanzania considering biofuels as an appropriate means to attract this investment (Sulle and Nelson 2009, Schut et al. 2010, GoM 2008). Yet, these investments must be made in a socially and environmentally responsible manner in order to avoid negative socioeconomic and environmental effects, such as livelihood displacements, poor wages, reduced livelihood opportunities, biodiversity loss or deforestation. These impacts are particularly of concern at the local level (Cotula and Leonard 2010, Cotula et al. 2009). It is also important to ensure that as much as possible of the return from the investment remains in the country rather than simply returning to the investor, but also that the returns are distributed in a more equitable way amongst the local people either employed in the large-scale plantations or participating in outgrower schemes. Use of a labour-intensive (with local labour) as opposed to a capital-intensive approach to project implementation would be one example of how a policy shift in investment approaches can stimulate greater distribution of benefits whilst also providing economic multiplier effects in the national economy (GoM 2008, Arndt et al. 2009).

\section{Value-added products rather than raw biofuel feedstock should be exported when servicing export markets}

Clearly maximising the national economic benefits from biofuel production is a priority. Where possible all value-adding should therefore take place within the country to produce finished products rather than exporting raw feedstock. This increases both investment and job opportunities within the country as well as increasing the value of the finished product. International and/or importing country trade regulations have, on occasion, provided perverse incentives whereby sellers achieve greater value by exporting raw produce.

The argument for local value-adding can be applied to the local context, with value being added where the biofuel feedstock is produced rather than the feedstock being moved to centralised processing plants in large cities; this would enhance the rural development aspects of biofuel production.

\section{Biofuel development should maximise the retention of financial benefits within the country}

Clearly it is beneficial to countries to retain as much as possible of the financial benefits from biofuel production. In addition to value-adding, other options can increase the retention of financial benefits, with mechanisms including promotion of high labour activities, taxation on profit, regulations on ownership, requirements for corporate social responsibility, spending and foreign exchange controls. A fine balance obviously exists between the ability to attract foreign investment, and the degree to which revenue can be retained in the country. African countries are predominantly poor, and citizens and governments do not have the financial resources to invest in expensive biofuel plantations 
and the processing plants needed to convert feedstock into biofuels. As such, foreign investment is critical. Investments that result in large numbers of well-paid jobs for local employees will, however, have far greater national benefits than developments based on highmechanisation and job opportunities for foreigners.

\section{Biofuel development must represent a net national economic benefit}

It is important that biofuels represent a net economic benefit to the country. Where biofuels have a net economic benefit, but are not financially attractive enough to attract foreign investment, a case can be made for incentives or subsidies to promote the industry. In essence this is the approach Brazil took to establish its biofuel sector. If biofuel projects are financially viable, but not a net economic benefit, then biofuel should be banned or discouraged. Determining net economic benefits is, however, complex as some of the costs and benefits such as environmental and social costs and benefits are difficult to account for (Harrison 2010b). Biofuel is a relatively unique development in that it has such a huge land-use footprint, and therefore is likely to have far higher social and environmental impacts than most other developments (Cotula et al. 2009). It is probable that a multi-criteria approach rather than a more simplistic financial approach is needed to fully understand the complete costs and benefits (Bazzani 2005, Bell et al. 2001, Dodgson et al. 2000).

\section{Biofuel development must lead to appropriate and sustainable land use}

Though biofuel feedstock production may be a technically feasible land use, the question needs to be asked whether or not it is the most appropriate land use in any given scenario. For instance, high-valued food crops may well have a better financial return and provide more job opportunities than relatively low value biofuel crops. A number of early biofuel reports suggested that biofuels may be an appropriate land use for degraded or marginal land (Openshaw 2000, Francis et al. 2005, Fairless 2007), and this was suggested as being a particular strength of jatropha. Experience, however, suggests that developers tend to target better quality land as this will give better returns, since all crops including jatropha respond to better quality soils. Yields from biofuel crops planted on degraded or agriculturally marginal land therefore might not be economically viable for biofuel production (van Eijck et al. 2010, Mengesha 2011).

Both national and international investment in new food crop production ventures is low in most African situations. By contrast, there is a recent demand for land for biofuel investment, especially from international investors. The biofuel investment, be it for large-scale or small-scale plantations, often brings financial and technical support, and in the case of small farmers, the promise of a market (Amigun et al. 2008). The possibility therefore exists that a relatively low valued biofuel crop (in terms of dollars or jobs per ha) may receive financial and technical support, whereas there is no direct foreign investment to support the establishment of more economically beneficial alternative food crops. In such situations careful consideration should be given as to whether or not the region should embark on biofuel simply because it will get support via direct foreign investment, or whether it should try more beneficial land-use options such as food production even in the absence of investment opportunities. A lower value, more secure investment may be better than a higher value, uncertain investment. There is relatively good evidence that outgrower crops that are supported by a mill succeed better than food crops sold into the open market (Vermeulen and Goad 2006). This is because the mill depends on feedstock to remain operational and it will therefore provide substantial support to farmers to ensure that they produce the required feedstock (Vermeulen and Goad 2006). This is particularly true for sectors where mills depend on large volumes of feedstock that need to be grown nearby to reduce transportation costs, as is the case with forestry pulp mills or sugar mills (Mayers et al. 2001).

\section{Biofuel development should link to modernisation of agricultural practices}

Low agricultural production over most of SSA is linked to poor agronomic practices rather than inherent poor production potential (Eswaran et al. 1997). Enhancing agricultural practices could simultaneously increase food security whilst freeing up land for biofuel expansion (Rudel et al. 2009). Infrastructure such as roads, fertiliser distribution networks and improved market access 
that is developed to support biofuels projects could also be used to enhance other agricultural production. In effect, this could result in a synergistic relationship where both agriculture and biofuels jointly develop through increased investment in the rural environment. The injection of cash into previously poor areas through the creation of jobs, shared transportation of agricultural inputs and the creation of markets for agricultural surplus could help prevent food/fuel conflicts and allow for the parallel development of both sectors. Introducing sustainable farming practices for feedstock, based on an agro-ecological approach (IAASTD 2008b) such as conservation tillage, may improve economic and resource use efficiency, thereby reducing the environmental impacts. There is also the potential for synergies and integration between biofuel feedstock byproducts, such as using jatropha seedcake as an organic fertiliser to improve agricultural production (Sinkala 2008, Tigere et al. 2006, Achten et al. 2008).

\section{Biofuel development should be environmentally appropriate}

A development-environment trade-off is inevitable where any development needs large tracts of land (von Maltitz et al. 2010). Most countries in Africa are signatories to the United Nations Convention on Biological Diversity (UNCBD) and as such biodiversity protection should be a priority. Numerous other environmental impacts could also potentially be involved including changes in hydrology, pollution and land use. However, economic development is also a huge priority throughout SSA, and policy makers are under stronger pressure to meet their development rather than environmental targets (Lerner et al. 2010). Numerous options are potentially available to reduce environmental impacts through careful planning and the way projects are implemented (von Maltitz et al. 2010). Biofuel development might also be able to slow some of the non-biofuel related drivers of environmental degradation resulting from rural poverty. For instance, many drivers for the unsustainable use of traditional fuels are linked to poverty; if biofuels help reduce rural poverty, they might also reduce the drivers of rural deforestation by allowing people to move to alternative fuels. Mitigation options to reduce or compensate for biodiversity loss can help ensure that high conservation areas are not only identified, but also protected.

\section{Biofuel development should not lead to a net increase in deforestation}

Deforestation rates differ extensively between countries in Africa but as a whole, deforestation in SSA is less than in either South East Asia (SEA) or Latin America (LA). High rates of deforestation are, however, common in many forested areas in Africa. The current nature of deforestation in Africa tends to be different from other regions and at present is not as strongly driven by large-scale agricultural and palm oil expansion as found in LA and SEA. Charcoal production appears to be a strong deforestation driver, though the true magnitude is uncertain (World Bank 2009, Mugo and Ong 2006). Deforestation globally is a major driver of $\mathrm{CO}_{2}$ emissions. In instances where biofuels are being targeted for international markets it is possible that they will not be certifiable if their production has resulted in deforestation with associated carbon emissions and biodiversity loss, e.g. the EU RED directive (EC 2009).

\section{Long-term sustainability}

Long-term financial, social and environmental sustainability is required for a viable biofuels initiative. Achieving this will require consideration of all of the above mentioned 16 desirable outcomes. Adherence to all national legislation is also important, as well as the minimum standards set out in the various certification standards where these are applicable. 


\section{A closer look at four types of biofuel development}

Each of the 4 project types identified in section 2 is considered individually in terms of the opportunities presented for biofuel expansion, establishment constraints and policy options for enhanced benefits.

\subsection{Type A: Large-scale liquid biofuel plantations}

Many of Africa's biofuel projects are linked to investors who have acquired, or are attempting to acquire, large tracts of land for dedicated biofuel plantations (Schut et al. 2010, GEXSI 2008, Friends of the Earth Europe 2010, Oakland Institute 2009, Graham et al. 2010) (Figure 2). Although actual land allocations have been smaller than what investors applied for, there are documented examples of requests for land for single plantations in the hundreds of thousands of hectares (Cotula et al. 2008 and 2009, von Braun and Meinzen-Dick 2009).

\subsubsection{Potential opportunities}

Most developed countries (especially in the European Union) are moving from voluntary to obligatory legislation in order to impose a market share for bioenergy in the transport sector and apply a mandatory blending legislation (Banse et al. 2008). To meet the blending target of about $8 \%$ by 2020 , EU countries would most likely need to import feedstock (and/or biofuel) from elsewhere, due to insufficient available arable land for energy crops and well-established regulations governing land use (Banse et al. 2008, Mohamed 2007). The international biofuel market has created an opportunity for largescale biofuel plantation development in Africa and a number of African countries have subsequently signed agreements with foreign investors to devote large amounts of land for bioenergy production (UNIDO 2009, Graham et al. 2010). For example, the last 4 years have seen Norwegian, Brazilian, Dutch, Swedish, German and British firms all competing for farmland to grow energy crops in different parts of Africa (Cotula et al. 2008 and 2009, von Braun and Meinzen-Dick 2009, Nnanna 2010, World Bank 2010). Large-scale projects have the advantage that they are quick and relatively easy to establish, and they can provide a relatively consistent volume and quality of feedstock. In addition, large-scale projects can be set up and run as conventional corporations, making it easy to set them up as companies with investor finance.

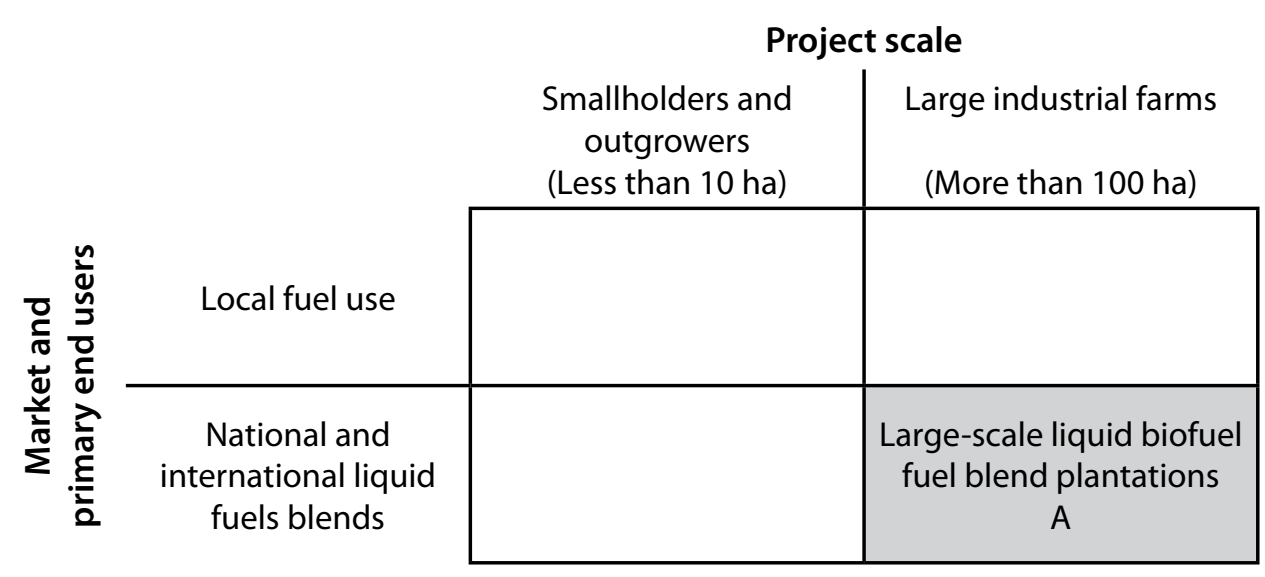

Figure 2. These projects provide feedstock from large-scale corporate plantations that is dedicated to national or international liquid transportation fuel blends 
SSA is in desperate need of development, and largescale biofuel projects are where investors seem keenest to invest. From a national perspective, attracting investors in biofuel processing facilities will be a better option than investors simply seeking to grow feedstock for export. Large-scale mills cost tens to hundreds of millions of US dollars to be established. In a Greenfield situation (i.e. a new project established that is not based on existing feedstock production), it is often not feasible to get small-scale farmers to provide the feedstock needed in the timeframes required. Hence the mills will either directly invest in large-scale feedstock production, or enter into partnerships with large-scale producers.

Land in Africa is comparatively cheap and some biofuel developments involve land-purchase by the developer. However, in practice many large-scale projects are established on leasehold land where the developer does not need to directly invest money in buying the property. In some instances, simply the fact that the developer is bringing development and job opportunities is considered as payment for the land although in other situations there might be onceoff or annual fees (Cotula 2011).

Large-scale plantations have the potential to create job opportunities in areas with little more than subsistence agriculture at present. Many areas in SSA have limited cash income opportunities, especially in rural areas where even selling agricultural surplus can be difficult (Haywood et al. 2008). Both from a national perspective as well as from a community member perspective, a large emphasis is placed on achieving paid employment.

Whilst international markets have historically been the main driver for large-scale biofuel, there is also the opportunity to develop national markets by introducing national blending targets. Brazil is a good example of how enforced national markets were able to create a huge biofuel industry (RosilloCalle and Cortez 1998, Koizumi 2005). Creating a local market helps to both reduce national foreign exchange expenditure and increase national fuel security. Foreign exchange expenditure on liquid fuels is often the single biggest foreign exchange expense in SSA countries, estimated at 20-30\% of total export earnings (Wolde-Georgis and Glantz 2009).
In Tanzania, oil contributes $40 \%$ of the value of total imports (Janssen 2006).

From a national perspective, these large-scale plantations are the most easily taxed and therefore can potentially contribute the most to direct tax income. Other production models will tend to have greater indirect impacts.

\subsubsection{Constraints to establishment}

A number of constraints make it difficult for biofuel investors to invest in large-scale biofuel projects in SSA. Accessing land remains a key consideration. This is linked to many inter-related issues including: dealing with customary land tenure; national land laws which might include ongoing tenure reform; the fact that most land is already either occupied or used; the need to negotiate at national, community and individual levels; long time delays due to the complexity of dealing with tenure issues; perceptions of long-term insecurity of tenure; and, market-based criteria (e.g. RSB) for how current land users should be treated.

A lack of access to capital is a concern, especially if the country where the investment is to take place is considered a high investment risk. These constraints were compounded by the credit crunch and declining oil prices, which saw many financiers withdraw their interests. The financial returns on biofuel can also be relatively low, making biofuel unattractive for investors (Van Eijck et al. 2010).

The financial feasibility of biofuel projects has been questioned in many situations. As a consequence many investors look for some form of state support to make the investments more attractive (Van Eijck et al. 2010). Costs of operating in SSA can be high; although there is abundant and relatively cheap manual labour, skilled labour may be in short supply and may be expensive. In addition infrastructure such as road networks and telecommunications may be poor so that the cost of infrastructure and other input costs can be exceptionally high.

Political instability and poor governance can increase the investment risks as well as the costs of doing business. 
Low investment in national research may mean that companies must undertake a lot of their own agronomic research associated with biofuel feedstock production. For newly introduced crops such as jatropha this means no information is available on critical aspects such as yields and management requirements, on which to base viability analysis.

\subsubsection{Potential impacts}

Large-scale corporate biofuel feedstock plantations have created the most concern in the literature around adverse socio-economic impacts, including the following:

- Displacement of current land users and their associated livelihood strategies (Cotula et al. 2008, Gordon-Maclean et al. 2008, Sulle and Nelson 2009, Vermeulen and Goad 2006, Schoenveld et al. 2010). This could also lead to a loss of culture and indigenous knowledge systems.

- Displacement of existing agricultural practices potentially leading to direct or indirect competition for production of food, fuel, feed and fibre (Woods and Diaz-Chavez 2007, Rajagopal 2007). The conflict with food production is of particular concern, especially as many SSA countries are net importers of staple foods; in 2000, the average total imported cereal demand in sub-Saharan Africa was 33\%, with Sudan, Gambia and Zambia reaching more than $80 \%$ (FAO 2008).

- Concern that the biofuel estate will produce fewer job opportunities than before the investment (Bickel and Dros 2003). So even though jobs may bring greater benefits to the individual, a net consequence is that a number of households become poorer. This problem is compounded if most of the jobs involve people who were not land users before the introduction of the project (Actionaid 2010).

- If mechanisation is used, this lowers the potential for jobs (Greenenergy 2008)

- Possible deepening of rural poverty and a loss of livelihoods amongst some in the community who were using the land before the project's establishment (Actionaid 2010, Wolde-Georgis and Glantz 2009).

- Loss in ecosystem services and reduced resiliency as a result of biodiversity loss and deforestation due to direct and indirect large-scale land use changes (Koh and Wilcove 2008, Koh and Ghazoul 2008, Sala et al. 2009, von Maltitz et al. 2010). Large biofuel plantations generally do not practise polycultures or intercropping and the large emphasis on single large-scale monocultures leaves few biodiversity corridors and buffer zones (which are often a feature of small, individual farms that have considerable on-farm biodiversity and a mosaic of agricultural land uses). Furthermore, the highly intensive agricultural systems often use considerable amounts of chemical fertilisers, herbicides and pesticides, which negatively impacts local ecology (e.g. freshwater reserves).

- Concerns that these developments are mostly driven by foreign investors with limited benefits retained in the country. This is particularly true if there is little value-adding and preprocessing in the country (i.e. the biomass is exported and processed to biofuel overseas) (Cotula et al. 2008 and 2009).

- Ownership is typically foreign, which brings limited national wealth creation and typically results in an inequitable distribution of wealth for local communities (World Bank 2010, Schutter 2009).

- Foreign labour may be used in preference to local labour. This is especially true for management positions, but could also happen with manual labour. This can exacerbate the inequitable sharing of benefits and reduced livelihoods.

- Concerns that many large-scale projects are aimed at exporting feedstock or biofuel rather than meeting local fuel needs, which results in missed opportunities for stimulating rural development (Wolde-Georgis and Glantz 2009, Pimentel et al. 2010).

Despite the above mentioned negative impacts concerning large-scale plantations, these large-scale operations have numerous benefits and in many situations may be vital for the establishment of a viable biofuels industry.

- Biofuel crop yields are typically higher per unit area in large-scale plantations than in small-scale plantations (e.g. in South Africa small-scale sugar producers tend to yield $20 \%$ less than large-scale producers (Ngapeh 2010)). In turn, African smallscale palm oil producers are producing about a 
tenth of Malaysian large-scale producers per ha. A consequence of higher yields is that the land footprint needed is smaller (World Bank 2010). This is, however, at the cost of high inputs such as fertilisers that have off-site impacts such as GHG emissions and power use.

- Increased scale reduces capital and operational costs (Amigun and von Blottnitz 2007, 2009 and 2010, Amigum et al. 2008, Cushion et al. 2010), although this can also reduce job opportunities as scale also tends to mean increased mechanisation.

- Large plantations often bring improved regional infrastructure such as roads, clinics and schools (Cushion et al. 2010).

- Creates rural job opportunities with relatively well-paid labour, in areas with limited access to cash income (IRGC 2008, Domac et al. 2005, Arndt et al. 2008 and 2009, Koh and Wilcove 2008).

- Salaries from large-scale producers tend to be far higher than those paid by small-scale farmers if they hire additional labour. Large-scale plantations in Brazil were found to pay above the minimum rural wage (Smeets 2008, Assad 2007, Moraes 2007). Permanent workers also often receive other social benefits.

- Large-scale producers can be more easily regulated on: (i) total extent of planting and the rate at which it expands (Koh and Wilcove 2008); (ii) linking conservation initiatives such as maintaining biodiversity migration corridors (von Maltitz et al. 2010); (iii) compliance with national legislation including tax and labour laws; and, (iv) compliance with market-based certification criteria (Harrison et al. 2010a).

- Complex indirect consequences of an enhanced rural economy, including the stimulation of outgrower producers, that might lead to greater food production efficiency (Rossi and Lambrou 2009, Cotula et al. 2008, CGIAR 2008).

\subsubsection{Policy options for enhanced benefits}

\section{Enhancing existing local livelihoods}

The impact on existing livelihoods during large-scale biofuel expansion is potentially one of the greatest concerns. Mechanisms that can aid in ensuring that positive benefits flow to local livelihoods include:
- Identifying all existing land users, taking into consideration that some use may only be seasonal or even only occur every few years.

- Achieving free and prior informed consent from those with a current claim to the land or its resources. This should include those with longterm usage of the land, even if they do not have formal ownership rights. Informed consent means that the affected parties must have a balanced view of the likely impacts and risks involved. It is probable that the affected community has unequal negotiating capacity, and it may be advisable to have an impartial mediator facilitating their involvement.

- A commitment to actively build skills and training in the country as a means to improve local skills and employment.

- Ensuring that local people have first option to job opportunities.

- If individuals are to be compensated for loss of livelihood opportunities, then a fair value needs to be calculated based on the long-term use values being forfeited. It must be borne in mind that these use values may have lasted for generations before the project, and the level of compensation needs to recognise this.

- Independent research should determine if the net benefits to local communities will be positive. Many resources that the community may lose are non-market benefits such as access to non-timber forest products such as medicines and foods as well as ecosystem services such as water. The value of these benefits to the local community and their livelihoods needs to be considered (Harrison 2010b).

Certification requirements are a powerful mechanism for ensuring that large-scale biofuel developments enhance local livelihoods. Since this type of project aims to sell biofuels to established markets, and the trend appears to be that major markets such as the EU will demand certification, companies have a strong incentive to be certified (Woods and Diaz-Chavez 2007, Vis et al. 2008, Diaz-Chavez 2010, Harrison et al. 2010a).

Legislation and especially tenure and labour legislation can be enhanced to reduce negative impacts. The state can legislate the requirements 
for the company's community engagement and the types of compensation for communities for their land and labour. In addition the state can play a monitoring role to ensure that companies are complying adequately, though the need is greatly reduced if companies have voluntary certification, as the certification agent will undertake most of the required monitoring.

State and NGO facilitation and oversight of land acquisition and community engagement can greatly reduce negative impacts. Capacity development, independent research, legal advice and contracting advice are some of the services that can be provided.

\section{Optimising national returns}

Because large-scale plantations are often set up through direct foreign investment, most of the profits leaving the country is a very real threat. Mechanisms to enhance the national benefits include:

- Requiring joint ownership with a limit on the extent of foreign ownership;

- Requiring a certain percentage of profit, or an agreed amount, to be spent on corporate social responsibility projects such as infrastructure, schooling, clinics, etc;

- Restrictions on exporting profits through mechanisms such as export tax;

- Increasing the amount of value-adding within the country (e.g. a project to simply export feedstock greatly reduces the potential national benefits);

- Promoting labour-intensive methods instead of mechanisation wherever feasible. The benefits to the country are far greater if the investment in a biofuels development is used to pay wages rather than purchase imported machinery.

Certification requirements are likely to provide relatively weak leverage for ensuring that these policy options are achieved. To achieve these benefits, legislation and financial incentives/disincentives are likely to be more appropriate. If the legislation is in place, then market-based mechanisms can assist in ensuring compliance as adherence to national legislation is a key criteria within any certification scheme. Making land acquisition dependent on these requirements is also an effective way of demanding compliance.
Increasing local ownership and equity of ownership It is common that large plantations are on leased land. The nature of leasing is country-specific, but in many instances the lease amounts are relatively small and in many, if not most cases, the lease payments go to governments, local government or traditional authorities. Alternative approaches to tenure and lease arrangements could increase local benefits and empower local communities. This can be achieved by:

- Enhancing individual or group tenure through tenure reform. This does not need to involve freehold tenure, but should ensure that existing land users have long-erm tenure security.

- Mitigating against the impacts of loss of land and land resources by ensuring timely, appropriate, and adequate compensation and long term development assistance to support livelihood reconstruction. This could be achieved through a transparent, consultative, and participatory land alienation process that subscribes to principles of free, prior, and informed consent and supported by the statute.

- Having lease agreements between corporate plantations and actual land users. In this instance the land user would receive a fixed lease amount per year to compensate for forfeiting their previous land use rights.

- Ensuring existing land users become shareholders in the company. For this to be appropriate they would need to control a substantial share and have a true voice in managing the biofuel projects, as well as receiving dividends from profits.

- Ensuring that if the company closes for any reason, including going into liquidation or selling to a new owner, then the original land users regain their usage rights. Biofuel estates should not be used as a mechanism for an in-perpetuity transferral of land from the community to the state (as has been reported in Tanzania (Valentino 2011)).

- Considering forms of (reversed) share cropping agreements whereby the community is the land owner (even if not in the truest sense of the law) and the corporation share crops on the land (unlike a straight lease, profit is a percentage of yield rather than a fixed amount). In other words both the 'land owner' and crop grower share risks and rewards (Silversands biofuels used this model in South Africa). 
- Considering forms of cooperative ownership of the estate, i.e. the current land users form a cooperative that runs the estate, possibly in a joint partnership with an external investor.

- Instead of one large foreign-owned estate, creating a large block of smaller, locally owned private commercial farms.

A mix of tenure reform and economic incentives could help drive these policy objectives. In Brazil the social seal approach is used to increase the share of small grower farmers (although the way this is formulated tends to promote the larger producers amongst the small-growers, with limited impact on the smaller producers) (Practical Action Consulting 2009). Certification, if not linked to appropriate legislation, will not be an effective mechanism for driving these types of changes.

\section{Mitigating biodiversity impacts}

Large-scale plantations tend to be monocropped on land that is totally cleared of natural vegetation, creating the potential for substantial biodiversity impacts. If biofuels capture a large share of the liquid fuels market, there will be major global impacts as vast areas will be needed. In the African context it is also important to realise that the status quo (i.e. not introducing biofuels) also has biodiversity impacts which need to be traded off against biofuel-induced impacts. Poverty, for instance, affects biodiversity, and biofuels may assist in reducing poverty. Potential mechanisms to reduce these impacts (see von Maltitz et al. 2010 for greater detail) include:

- Ensuring that strategic conservation planning has identified important biodiversity hotspots.

- Planning plantations to avoid biodiversity hotspots using, for example, the High Conservation Value (HCV) approach.

- Including strategic biodiversity buffer zones and migratory corridors in the plantation plan.

- Using mitigation options to offset unavoidable biodiversity loss. For instance, include surrounding endangered habitats in the biofuel estate so that the area can be well managed and conserved

- Locating biofuels preferentially on degraded land. Note that degraded land has often already lost most of its natural biodiversity and must be clearly differentiated from low production land that might still hold high amounts of biodiversity.

- Locating biofuels on abandoned crop land. Note that if the abandoned crop land is likely to be used for cropping again in the foreseeable future, then the biofuel expansion could lead to indirect land use change.

- Locating biofuel on crop land and simultaneously increasing the crop yield on surrounding crop land (through intensification), so that the total crop yield remains constant or increases. If total crop yield decreases, then indirect impacts on land use change and biodiversity are possible.

- Taking due consideration to prevent the invasion of alien species (see IUCN 2009 guidelines) and adhering to relevant national phytosanitary and plant importation legislations.

Certification standards such as the RSB can have a powerful influence on reducing biodiversity loss. They are strongly enhanced by clear national conservation planning strategies and national biodiversity prioritisation. Proper applications of Environmental Impact Assessment (EIA) processes should also help prevent biodiversity loss. Proper biodiversity planning goes beyond what can be expected of individual biofuel projects and the state or international conservation bodies should provide assistance in developing the strategic framework (Harrison et al. 2010a, von Maltitz et al 2010).

\section{Preventing deforestation}

Deforestation causes biodiversity loss (see discussion on biodiversity above), loss of livelihood opportunities (see discussion on livelihoods above) and increased carbon dioxide emissions. Where biofuels are being grown to mitigate climate change then the carbon release is a critically important issue, especially if biofuels are destined for sale to the EU where the EU RED directive (EC 2009) sets out carbon criteria. Where sales are to national markets and/or international markets that are not driven by GHG reduction requirements, then the carbon impacts may be less critical. Both direct and indirect deforestation impacts need to be considered. There are also many complex direct and indirect feedbacks so in a country considering large-scale biofuel, it is 
the overall or net country deforestation impact rather than the specific plantation impact that may be more important. Some possible mechanisms to reduce deforestation from large-scale plantations include:

- Limit biofuel to non-forest areas. Note that this may reduce forest loss, but could indirectly cause deforestation by displacing food production into forested land. Non-forest land such as grasslands may also have high biodiversity so though there may not be deforestation, there could still be biodiversity impacts.

- Siting feedstock plantations on already degraded land.

- Considering the use of biofuels as a mechanism to reduce other forest loss drivers (as explored in greater detail in section 6). In most African countries traditional fuel usage is a big deforestation driver, especially charcoal production. If biofuel can be used as a partial replacement for charcoal then this may actually reduce deforestation. Equally, changing the socioeconomic conditions that lead to traditional fuel use or introducing more efficient methods to use the biomass might reduce the pressure on traditional fuels.

Certification criteria such as the RSB place a lot of emphasis on carbon balance and direct deforestation impacts. Very little or no emphasis is placed on secondary feedbacks including indirect land use change, or indirect reduction in deforestation. National level intervention including financial incentives, awareness raising and education could assist in promoting the use of biofuels over traditional fuels (this concept is explored in more detail in section 6).

\section{Reducing food fuel conflicts}

Food availability could be hampered by biofuel production since the large-scale use of land could pose a threat to the same land and water resources being used for food production. The fact that largescale plantations will largely employ farmers as their labour force can also lead to reduced food production on existing farms. Possible mechanisms to reduce these impacts include:

- Integrated local and national land-use planning that ensures land and other resources are adequately allocated to optimise and prioritise food production.

- Developing a strong food crop farming sector by intensifying agricultural practices could potentially free up vast tracts of agricultural land whilst simultaneously increasing national food security, though could increase risks associated with dependency on inputs. At a national level governments need to understand what is suppressing current food production, and then deal with these constraints through appropriate mechanisms. This has little to do with biofuel, though the biofuel issue can potentially provide an opportunity to engage in this debate.

- Analysing the constraints in national and international policy that impact on national food security, to make appropriate adjustments for a supportive environment that stimulates the food production sector. For instance, increasing agricultural research, development and extension; reforming land legislation; and providing appropriate subsidies, may stimulate food production. Allowing cheap importation of food and high agricultural taxes may depress the foodproducing agricultural sector.

- Zoning areas for biofuel production to prevent prime agricultural areas being converted to biofuels crops.

- Providing workers with some flexibility to enable them to tend to their farms (this is being practiced by some projects in Mozambique).

- Growing food crops on the plantation, through, for instance, intercropping, which is made available to employees in addition to wages (though this must be done with extreme caution as it may negatively impact on local food markets and disadvantage local small-scale farmers).

- Ensuring labour wages are sufficiently high to offset the losses from reduced home food production where subsistence farmers have given up farming to enter the biofuel labour market.

- Banning staple food crops from being used as biofuel feedstocks. Although this mechanism is widely proposed and implemented, whether or not it has the desired impact is hotly debated. For instance, South African maize farmers argue that a maize-based biofuel sector would bring stability rather than reducing food maize. However, this view is contentious as it may work 
in years of good production and rainfall, but may be problematic during drought years because the poor set the price on the margin but cannot compete in a market with large biofuel producers who will push up the price to ensure market access and dominance.

Indirect impacts between the food and fuel sectors are complex and poorly researched. However, the increase in infrastructure and market access, available income to farmers, development of local markets and many other factors could stimulate local food production, improve livelihoods and facilitate a shift to higher yielding farming practices (Rossi and Lambrou 2009, Cotula et al. 2008).

Most aspects of food insecurity in Africa have occurred in the absence of biofuel and there is an urgent need to understand and remedy the root causes of food insecurity. This should be done regardless of biofuel developments, but biofuel may provide a lever or catalyst for assessing and dealing with some of these issues (Haywood et al. 2008).

Most aspects of food/fuel conflict are difficult to manipulate through certification, though the RSB does specifically raise this as an issue for consideration in food insecure regions. Whereas aspects such as a fair wages and fair working conditions can be relatively well influenced through certification, monitoring food insecurity changes related to biofuel expansion would be complex and difficult to implement within a certification framework.
Government support for, and enforcement of, zoning can entrench zoning as a mechanism. Government can also allow or ban feedstocks for use in biofuels where appropriate. A key government intervention is the creation of a policy environment to stimulate a vibrant food production sector.

\subsection{Type B: Small-scale private farmers and outgrowers to produce feedstock destined for the national or international liquid fuel blends}

Small-scale biofuel producers growing feedstock for national or international liquid biofuel blends (Figure 3) operate in a vastly different environment to the large-scale plantations. Although they may often be linked through contracts and markets to the largescale producers, most issues affecting these smallscale growers are different. Most sugar cane-based biofuel initiatives are still in the planning phase, but most envisage at least part of their feedstock will come from small-scale outgrowers (Vermeulen et al. 2009). Linking outgrowers to large-scale producers is well established in the sugar-for-food industry in South Africa, Tanzania and Kenya (IOS 2008). In Tanzania and Kenya, small-scale sugar farms are sometimes set up as dedicated blocks subdivided between individual farmers, as sugar is not suitable for growing in a mixed farming model on smallholdings (Matango 2006, ISO 2008). In South Africa, the small-scale farmers who grow sugar tend to dedicate all their farming activity to this crop (unpublished data).

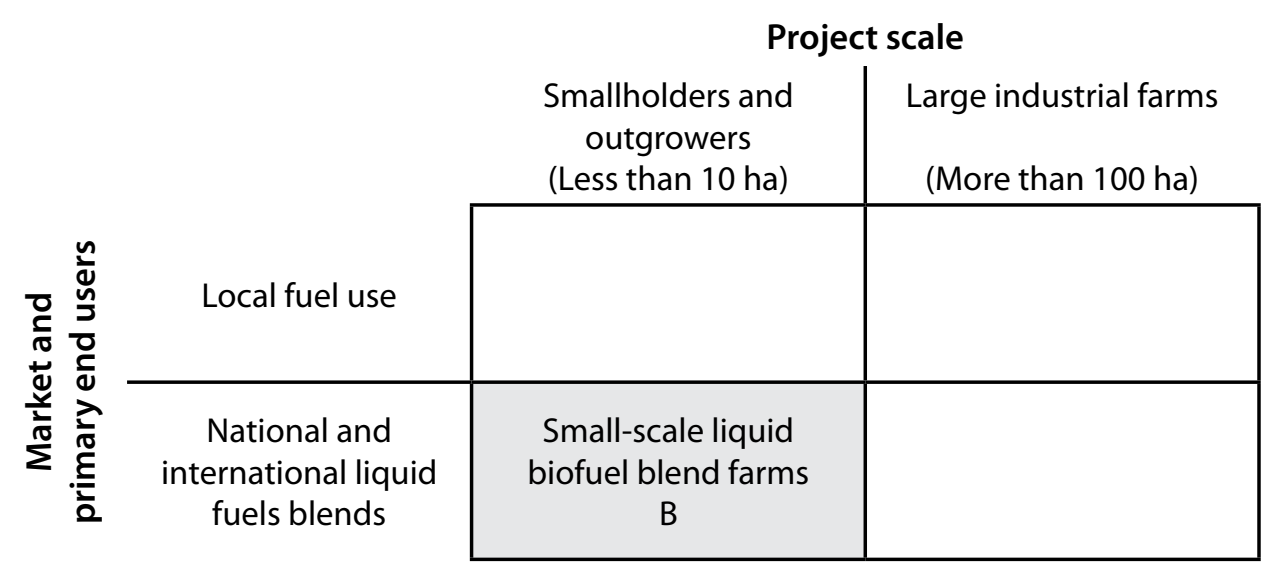

Figure 3. These projects provide feedstock from micro to small-scale farms that is dedicated to national or international liquid transport fuel blends 
In the case of Jaropha, small-scale farmers tend to farm jatropha as a cash crop within a mixed farming enterprise (Haywood et al. 2008, German et al. 2010). The plantation is often set up under contract to Jatropha seed-collecting companies, though some farmers set up their own plantations, which probably costs little more than the labour opportunity costs. To date, small-scale jatropha growing has not produced many tangible benefits to the small-scale growers as plants are not producing high yields, markets seem insecure and the industry is not meeting its contractual obligations (Haywood 2008, German et al. 2010a). It is important when discussing small-scale farming options to identify what are jatropha specific issues verses overall issues relating to contract and small-scale farming in general. Poor understanding of jatropha management and yields as well as the use of unimproved and untested germplasm may well disadvantage current small-scale jatropha farmers. It appears that many of the original contract farming jatropha projects where set up with limited information on the dynamics of jatropha growing. A lack of appropriate regulation also appears to have allowed companies to set up contracts with unfavourable conditions for the farmers. The companies in some instances also appear to not have fully met their contractual requirements in terms of guaranteed prices and ensuring a market.

Oil palm plantations in West Africa are also often on small-scale farms in mixed agroforesty systems. Currently most African oil is used for the food rather than fuel market. Currently most small holders are growing old, low yielding (unimproved) palm varieties (Vermeulan et al. 2009). Many small-scale African palm-oil farmers market through networks of intermediatories rather than being linked as contract farmers to large-scale processing facilities.

Though experience with biofuel small-scale producers is relatively limited, there is extensive African experience from other crops being grown by smallscale farming either as private individuals or through contract farming agreements. An important finding is that there can be many negative impacts from contract farming (see below section 4.2.3) and it is important that government provide a legislative framework that protects the rights of the smallscale farmers, but without becoming over restrictive (Eaton and Shepherd 2001, Simmons 2002). Small- scale farming is, however, a powerful mechanism for driving rural development and there are many examples of successful small-scale farm development in Africa. Small-scale tobacco production has proved very profitable to farmers in Zimbabwe and Malawi, despite unhappiness around the auction system used for sales in Malawi (Nisiku and Botha 2007). Similarly the small grower sugar sector in South Africa, Tanzania and Kenya has been very successful, though it is only in Kenya where this sector dominates production with large-scale producers predominating in the other countries (ISO 2008, Collin 2007).

Studies in the Zimbabwe have shown that small-scale producers in close physical proximity to large-scale producers tend to perform better than more distant small-scale producers due to formal and informal links between the large and small-scale producers (McIndoe-Calder 2011). In all these studies a key feature of success appears to be linked to the high value of the crop, something that Bijman (2008) also identifies as an important ingredient for contract farming. Secured market access and support is also important - market access having historically been a barrier to small-scale tobacco farming in Malawi where auction houses demanded a minimum volume. In this instance the use of intermediate buyers overcame the obstacle, but this decreases the profit to the farmer (Nisiku and Botha 2007). Though there are cases of high yields from the small-scale sector, in most instances small-scale farmers produce less per hectare than large-scale, mostly due to lower levels of inputs. Small-scale producers of staple food produce do not do as well as producers linked to export markets or industrial crops, and as Nsiku 2007, reports for Zambabwe, few produce a marketable surplus. This difference in success between staple food production and exported and industrial crops would appear to be partly related to the relative profitability of the crops, bat also largely to the support provided by the respective industries, including the guaranteeing of a market.

\subsubsection{Potential opportunities}

The international and national market opportunities for biofuel destined for mandatory blends that apply to large-scale plantations apply equally to small-scale plantations. However, the introduction of large-scale plantations and biofuel processing facilities provide the greatest opportunity for a small-scale biofuel 
sector to emerge and develop. From the industries' perspective, supporting a small-scale feedstock producing sector has many advantages. It takes away the burden of needing to acquire, hold and manage large tracts of land. Supporting outgrowers is often viewed favourably by the country in which the biofuel project wishes to invest. It is also viewed favourably by the market, especially where certification is required. Most importantly it allows the processing mills to access more feedstock than is possible from the amount of land allocated to their largescale plantations.

The mills' financial viability or profit margin depends on their throughput; it is in their best interests to support the outgrowers who are providing their feedstock. As a consequence, mills are prepared to provide services to the outgrowers which could include short-term loans, assistance in obtaining inputs, technical assistance and logistical assistance such as transport. Industry-supported outgrowers tend to have an advantage over farmers who rely on agricultural extension services, although the unsupported growers may be able to get higher profits (Richardson 2010). Contract based farming where the small-scale famer enters into a contractual arrangement with the processing mill can take many forms, but in general gives the small-scale farmer both a secured market and access to technical and/ or financial assistance. Research in the agricultural sector has found that contract farmers typically have higher income and higher profit than non-contract farmers (Bijman 2008).

\subsubsection{Constraints to establishment}

Outgrowers tend to have fewer land tenure constraints than large-scale plantations, especially if the outgrowers are going to plant feedstock on their existing farms, but may find it difficult to increase the size of their land holding. Where new blocks of land are being opened for outgrowers, their constraints will be similar to the commercial plantations. Establishing an outgrower supply chain is, however, an expensive and slow exercise, with no guarantee on uptake levels. The funding model for small-scale farmers is also complex, with high transaction costs as a consequence of the number of individuals involved. Farmers are typically risk-averse, so though some individuals may start growing biofuels from an early stage, most will wait until they can see the benefits before engaging. In the case of jatropha growers in Zambia, most farmers only planted a fraction of the area requested of them when first trying Jatropha (Haywood et al. 2008).

Poor education amongst smallholders and a low level of understanding around new crops and new markets is a constraint to new crop introduction. Most farmers have had no formal agricultural training and often very limited formal schooling. This is a constraint on communication and the setting up of contracts.

From the biofuels industries perspective, developing large corporate plantations may be an easier and more secure way of rapidly accessing feedstock. The industry may not choose to go the small-scale grower route unless there is an incentive to do so. The transaction costs of dealing with a vast number of small-growers can be potently large, and risks of not accessing sufficient feedstock are high. In addition, accessing DFI funds for small-scale production may be harder than for the establishment of a corporate plantation.

\subsubsection{Potential impacts}

Though micro and small-scale producers overcome many of the social constraints on ownership equity that can occur in large-scale projects, they in turn introduce their own unique problems. Small-scale biofuel farmers are relatively recent in SSA, but there is long-term experience of outgrowers in other food and fibre crops. Despite small-scale farmers representing far greater equity of ownership, this does not necessarily mean that small-scale farmers are not exploited and that they do not exploit their labour (Richardson 2010). Some concerns about small-scale biofuel farming models include:

- Labour, including household labour, can be far more easily exploited on small farms versus corporate estates. Small-scale growers tend to pay below national minimum wages and offer no other corporate social benefits. Children also commonly assist in farming activities on subsistence farms, a practice that would not be allowed on corporate plantations (Porter and Phillips-Howard 1997).

- Biofuel yields tend to be lower, and therefore the overall land transformation footprint to achieve 
the same level of production is higher than for large-scale plantations (Ngepah 2010). However, this might be slightly offset through intercropping or the use of agroforestry systems where a diversity of products is being produced and the net productivity may be higher.

- Farm labour and land has to be split between biofuel and food production. This may reduce household food production and affect food security. This issue is further complicated by differing gender roles in food and cash crop production, and who in the household has access to the profits from cash cropping. There is a real threat that women's labour demands might be increased whilst men may have greater access to benefits such as the cash earned (Haywood et al. 2010).

- Farmers are often under contract to mills or other corporate buyers. The nature of these contracts has been found to bind the farmer to agreements with very long periods (up to 30 years) as well as having other potentially unfavourable clauses such as restricting market access, low levels of support and penalty clauses (Haywood et al. 2008, German et al. 2010a).

- The farmers carry high risk, especially where markets for the feedstock have not yet developed. There are reports that farmers are unable to sell their jatropha seeds despite having contracts that promised a market (German et al. 2010a). If the farmer cannot sell his crop, or receives less than anticipated, this is his loss.

- Either due to contract clauses or distance, farmers often only have access to a single market. This takes away their bargaining power. For example, many jatropha growers in Zambia are committed under contract to sell only to a single organisation (Haywood et al. 2008, German et al. 2010a). Similarly, sugar cane farmers in Mozambque are limited to only one mill within reasonable transport distances.

- The small-scale operations often increase capital and operational costs. For instance, fertiliser and pesticide costs are far higher when purchased in small quantities and transporting small quantities can be more expensive (Ngepah 2010).

- Income to the farmer may be low. In fact, to date, experience with jatropha been very poor and some farmers are reporting low yields, greater than expected input costs (including labour) and non-existent markets or a low market value (Haywood et al. 2008, German et al. 2010a, Schoneveld et al. 2010).

- A lack of processing capacity can lead to an oversupply of feedstock (as happened in the Kenyan sugar industry), which results in the offered prices plummeting, or the loss of markets. If there is only one mill within an economically viable radius, it is difficult for the farmer to sell elsewhere yet the mill is most likely to first take feedstock from its own plantations (where it has these) and only use smallholders to make up the shortfall.

- Small growers are not necessarily given adequate and unbiased advice when entering into biofuel production. This seems to have been especially true for jatropha production projects.

- Some companies impose conditions for participation in outgrowers schemes. This could lead to an inequitable distribution of benefits as the most marginalized farmers are excluded from participation (Takane 2004; Fold 2008).

Producing feedstock on micro to small farms rather than in corporate plantations has a number of benefits, particularly from a developmental perspective:

- A great increase in equity of ownership, and also greater national ownership rather than foreign ownership;

- Manual labour is more likely than mechanised labour, so increasing job opportunities;

- Less likelihood of displacement of existing land users by new land users (though this could still be possible in some circumstances);

- Farmers diversify their farming activities and this could lead to greater on-farm biodiversity and resilience of the farming enterprise;

- Biofuels may bring cash income into areas with very low access to cash income. Investigations in Zambia suggest that marketing food crops for cash income gives very low returns, and that even low yields from a biofuel crop might give better cash returns to the farmer (Haywood et al. 2008, Borman et al. in press);

- From the biofuels mills' perspective, there is no need to purchase or lease vast areas of land. This 
greatly reduces the finances that they have tied up in assets;

- It provides for mechanisms to develop relationships between the large-scale farms, biofuel mills and the surrounding community;

- Because mills depend on maintaining a high throughput to maintain profit margins, it is in their best interests to support the small growers, and so small outgrowers tend to have far better financial and technical support than farmers producing food crops;

- Farmers can shift their crop production at any time when the arrangement is no longer working; assuming there are no long-term contracts preventing this;

- Easier access to inputs could increase overall farming productivity.

\subsubsection{Policy options for enhanced benefits}

\section{Evidence-based research to underpin programme}

It has been especially true for jatropha, but is probably also true for other feedstocks, that 'developers' persuade small growers to undertake biofuel projects based on claims of high financial returns, low labour requirements, and so forth. In jatropha's case, it is clear that the actual costs and benefits are very poorly understood and farmers have been somewhat misled. To prevent such problems, the following should be considered:

- Technologies should not be recommended for large-scale adoption before they have been rigorously tested firstly using station trials and then on-farm trials.

- The socio-economic implications of the on-farm feedstock production need to be investigated, including impacts on household food security, net income and labour allocations.

Financial support to conduct appropriate research is required to develop appropriate biofuels development models and policy support. In addition, policy needs to limit the widespread introduction of untested technologies, so that large-scale applications can be assessed and introduced as a function of technology maturity with a preference for robust and easy to maintain systems.

\section{Where contracts are used, farmer's interests need to be protected}

Illiterate or semi-literate farmers are entering into contracts set up by corporate entities and these farmers often do not have access to legal advice. Although investigations show that farmers are often aware of key contract conditions (Haywood et al. 2008, German et al. 2010a) they are not aware of all contract clauses nor are they aware of the consequences of defaulting. Assistance for farmers in contracting is needed and this could include:

- Legal limits on the duration of contracts;

- Legal assistance to ensure that farmers have a fair voice in the contract conditions;

- Requiring contracts to be vetted by an independent party or NGO that can act on behalf of the farmers;

- Assisting farmers to form cooperatives that can then negotiate on behalf of the farmers, giving the farmers far stronger negotiating power;

- Ensuring farmers fully understand contract terms.

Funding structures are needed to support legal assistance for farmers. NGOs can play a large role, but they need a political climate that empowers them to do so. Agricultural extension officers could also play a very useful advisory and facilitating role to assist farmers with contracts if the officers are properly trained.

Where small farmers are being certified, the certification process should audit the nature of contracts and whether a free and fair process was used during the awarding of contracts.

\section{Preventing monopolies}

The nature of biofuel developments means that competing mills are likely to be established relatively far from each other, with each mill having a unique feeder area. A consequence is that the mills effectively hold a monopoly on markets and can hence lower the price they are prepared to pay for feedstock. This can be avoided by:

- Discouraging long-term contracts that will not let the producer change to a new purchaser;

- Allowing for more than one mill to operate in an area; 
- Having legislation that prevents monopolistic practices;

- Increasing local storage and processing facilitates that can be used to diversify the value chain whilst also helping to regulate the market price;

- Adoption of equitable and transparent pricing formulas.

These interventions would require legislation to make them effective. Certification criteria could be used to monitor whether companies are using monopolies to underpay small-scale producers.

\section{Enhancing the bargaining power of smallholders}

Individual smallholders have very limited bargaining power. They typically have limited formal education, and due to poverty are very eager to link to any development that can potentially improve their living standards. The following can assist in increasing the bargaining power of smallholders:

- Formation of smallholder cooperatives or associations, companies would then need to negotiate with grower associations rather than individuals;

- Incorporate a union and shareholder structure into the biofuels company so that smallholders/ farmers are represented and the local ownership, investment and bargaining power improved;

- Incorporate a social improvement and skills development programme into the biofuel project to improve life skills and education;

- NGO or government assistance to represent the smallholders during company negotiations.
These changes are not necessarily in the best shortterm interest of feedstock buyers, so it is most likely that government or NGOs would need to assist communities to organise themselves.

\section{Education of smallholders}

Education of smallholders on opportunities, constraints, agronomic practices and their rights when entering into agreements would assist in empowering small-scale farmers to make informed decisions.

\subsection{Type C: Small-scale local energy plantations}

The small-scale sector providing biofuel feedstock for local energy requirements operates under a very different set of circumstances from the smallscale sector linked to commercial biofuels. In this model, it is typically a government initiative or NGO initiative that starts the project. The project aims to provide fuel, often as electricity, to the local community. The project's management is often a community initiative, although a local utility may be formed to administer this. Overall, the project is likely to have limited resources and although extensive outside resources may help to establish the project, over the long term most management will be local with financial sustainability depending on the local community being able to afford to purchase the new energy source. These projects can be seen as rural development initiatives rather than private sector-led commercial initiatives, despite the fact that these projects are typically set up on commercial

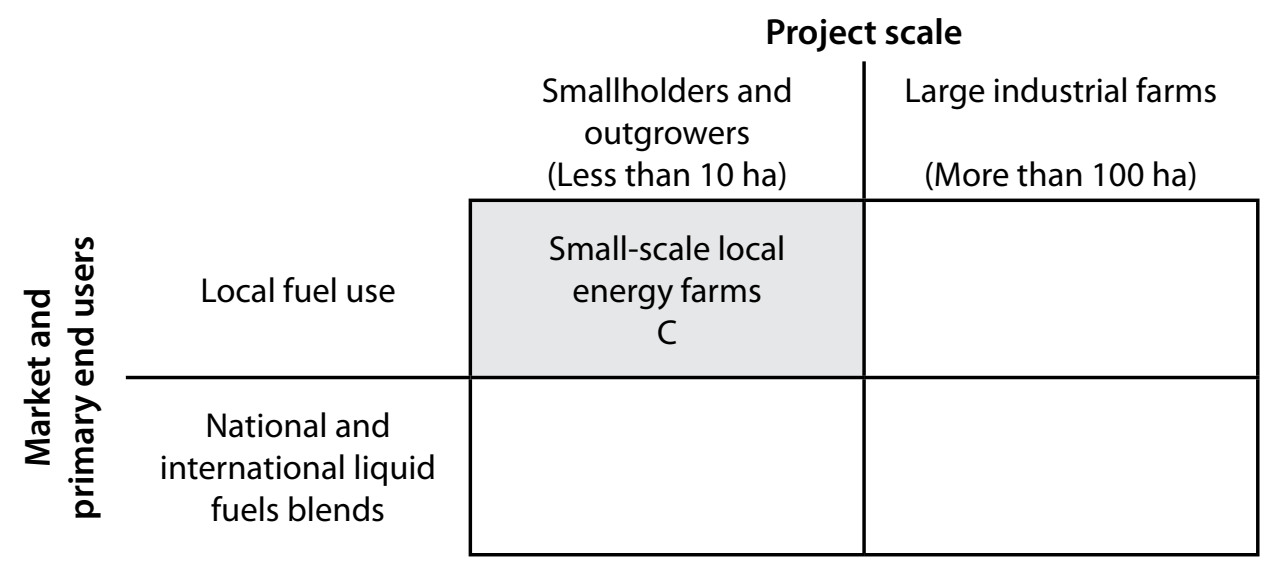

Figure 4. These projects provide feedstock from micro to small-scale farms that produce biofuels to meet household or local village energy needs 
principles. Since these projects are not providing fuel to an external market, market-based certification mechanisms are an inappropriate mechanism for regulating behaviour in this sector.

Probably the best known and best documented project of this nature is the FACT Foundation project in Garalo Mali. In this example jatropha is been grown by small-scale farmers and then sold to a locally run power utility to power marine generators to produce electricity. The electricity is then distributed to the local community (Wijgerse 2008). Currently the project uses predominantly fossil diesel as the local jatropha production is insufficient to fuel the project (own observations). jatropha is being advocated to fuel multifunction platforms in Tanzania using a similar model to that in Mali. The Gaia movement is attempting to use ethanol produced from small-scale distilleries for local cooking in Ethiopia and Brazil (Mengesha 2011). This use of ethanol for fuel gel has also been investigated for Tanzania (Zuzarte 2007).

\subsubsection{Potential opportunities}

Using biofuel for local fuel provision is a powerful mechanism for driving rural development. Not only does it bring modern fuel to deeply rural areas, but it does so in a way that creates numerous local job opportunities in the process. Income that local villagers would previously have spent on imported energy (such as paraffin or diesel) is now used to pay local labour in the village and surrounds and to drive local enterprise creation (UNDP 2005, Gaunt 2005, Karekezi and Majoro 2002, ESMAP 2000).

In many cases, using local crops as an energy resource results in increased efficiency of resource usage and reduced environmental impacts in the entire bioenergy life cycle.

Making modern energy available is considered to be an effective mechanism for driving development. For instance, a simple electric light can make it far easier for a school child to read at night, something that is difficult by candle or kerosene lantern. Equally, many small industries dependent on electrical equipment can be established.
The use of biofuels to supplement or replace traditional woodfuels could potentially reduce some of the deforestation pressures discussed in more detail in section 6.2.2.

\subsubsection{Constraints to establishment}

These projects are unlikely to attract industry funding (other than through social responsibility commitments) as the projects are unlikely to deliver a high rate of return to an investor. In fact, most of these projects will not have any profit motivation, but may simply be financially self-sufficient. As such the corporate sector will not invest in these projects and alternative funding streams will have to be sought.

Facilitating and funding the setting up of local energy projects is a socially complex and expensive task. The farmers are not providing feedstock for a corporate entity, and as such there is not the strong financial pull from a commercial processing mill to support the sector. The rural areas where these projects are typically aimed have a weak purchasing power that may be insufficient to support the initiative. In the case of jatropha-based projects, the yields to date have been lower than expected and most projects use fossil diesel as a substitute.

Only time will tell if the jatropha option is viable from a biophysical and socioeconomic perspective. The human skills and capacity to manage what are in effect quite complex biomass to bioenergy processes is probably lacking in the areas where they are targeted. This includes the agronomy skills for new crops, technical skills to operate and maintain relatively complex machinery, and management and financial skills to maintain a power utility.

\subsubsection{Potential impacts}

These projects are not expected to have the same sorts of negative impacts as might be found in projects aimed at the biofuel blending market. The quantity of power (available watts per consumer ) may be less than is provided by the national power grid. For instance, in the FACT Foundation project, the average household would only get 260 watts for a few hours per day (Wijgerse 2008). The cost of biofuel may be higher than that from large-scale biofuels projects 
due to economies of scale. Therefore, careful needs assessment, projection and planning is required when determining the capacity of local power grid systems (microgrids and minigrids).

These projects are aimed at local fuel provision, either through reducing local energy costs, or replacing a more traditional fuel. In particular electricity is often used to replace kerosene lamps and hence provide superior and more convenient illumination as well as providing access to numerous electrical appliances such as cell phone chargers and televisions. Pitfalls and benefits of this model include:

- These projects will only be sustainable if biofuels can be produced cheaper and/or deliver greater non-monetary benefits than imported fossil fuels.

- The biofuels are unlikely to compete with local 'free' fuels such as firewood for energy intensive tasks such as cooking. Therefore, although biofuels are modern fuels suitable for some functions, they may not fulfil all energy needs and may not necessarily reduce deforestation.

- These projects are often strongly reliant on an NGO or government programme, and if this support stops they may collapse. Current projects have all been initiated through strong commitment from outside organisations and dedicated individuals.

- Energy carriers and electricity brought into areas with poor infrastructure and that are too remote to have access to the national power grid.

- Liquid fuels that are potentially competitive with fossil fuels.

- Potentially improved livelihoods by reducing rural energy poverty and rural economic poverty through direct livelihood opportunities in producing biofuels and indirect benefits from small enterprises development (UNDESA 2007).

- Local labour to produce what would previously have been purchased from outside the community; hence returning cash to the community and stimulating the local economy.

- Local income generation activities in deeply rural areas with limited opportunities.

- Electrification of remote areas that are unlikely to get electricity grid access in the near term.

- Access to electricity can potentially stimulate a host of energy services and the development of new secondary industries that depend on electricity and waste heat from the electricity generation process.

- Diversifying farmers' cash generating opportunities and potentially increasing resilience by reducing dependence on external inputs.

\subsubsection{Policy options for enhanced benefits}

Note: all policy options for enhanced local energy provision depend on state intervention. Certification is seen as having very limited relevance to this type of project as a mechanism for driving sustainability

\section{Expansion from pilot projects}

Replicating projects once an operational pilot is established is far cheaper than the establishment of the initial pilot. Assuming pilots show that the technology is viable, then replication should be quite easy. However, strong government and donor support is likely to be needed to make this possible.

\section{Considering new fuels and transformation pathways}

Converting jatropha oil to electricity is an inefficient and potentially quite expensive mechanism for creating electricity. Alternate options, though often requiring greater investment, may provide enhanced benefits. These include gasification of dedicated fuelwood plantations and the use of ethanol for cooking (see section 5.2).

\section{Expand from local use to sale of energy}

As technologies for rural local energy provision mature, there is the possibility that successful projects can expand to sell their surplus energy. Using overengineered production facilities and/or ensuring a modular design could help facilitate this process. The energy could be in the form of electricity or liquid fuels. This option would bring new revenue sources to the community and would create a wide variety of job opportunities in fuel production, processing and sales (e.g. Amigun et al. 2006 and 2008; Zuzarte 2007).

\section{Carbon funding to increase viability}

The ability to tap into carbon financing for reduced emissions may enhance financial viability. If these projects could be demonstrated to reduce deforestation then this could enhance the carbon benefits; this is unlikely in the jatropha-to-electricity 
implementation model, but may be viable for an ethanol gel or gasification model (see section 5.2).

\section{Identifying new funding models}

Despite the significant rural development benefits from this type of project, funding and technical support will remain a critical constraint to large-scale uptake. State funding to these projects may be far more cost effective than providing grid electricity and hence justify subsidies equivalent to the costs of alternative electrification options. Many benefits will occur across the responsibilities of many government ministries and cross-ministry collaboration could reduce overall costs to a single ministry. In addition there may be alternative funding models based on private sector involvement (possible supported by favourable state incentives), or direct private sector investment through the development of a model that is fully financially viable, for instance facilitated through the use of technologies that open up options for the sale of surplus energy as discussed above.

\subsection{Type D: Large-scale local energy plantations}

These projects differ from the large-scale projects in type A in that they are designed to provide energy to a local enterprise, and are run as a component of the local enterprise (Figure 5). They are developed to reduce operational costs rather than to make a direct profit in their own right.

Very few examples of this project type were found, though informal discussions suggested that a few mining houses and large corporate farming ventures are considering this model. An operational example is in the Muzizi Tea Estate tea plantation in Uganda. Here, short rotation forestry is used in a heat and power operation, where heat is used in drying the tea and the power is derived through a gasification process; about $200 \mathrm{~kW}$ is produced and used for the plantation's electrical needs. The timber used for the biofuel is grown on a dedicated part of the tea plantation's land (Buchholz and Volk in press).

\subsubsection{Potential opportunities}

Mines, large commercial farms and plantations in deeply rural areas of SSA suffer from poor access to fuels, be it petroleum or electricity. Fuels tend to be exceptionally expensive due to transportation costs, and may well be unreliable due to poor infrastructure. Electricity undersupply in many countries including Zimbabwe, Zambia and Uganda, results in rolling blackouts, so companies cannot rely on the national grid. This gives a unique opportunity for biofuel development as it improves the biofuels' cost effectiveness and energy security compared to petroleum alternatives. In essence, biofuel production can reduce operating costs as well as improve the reliability of supply. In addition, it can potentially improve the public relations image of the core industry with surrounding communities by providing increased job opportunities. This model could also potentially be linked to outgrower schemes, further expanding local community benefits. This may also help rehabilitate degraded land, particularly in the case of decommissioned mines.

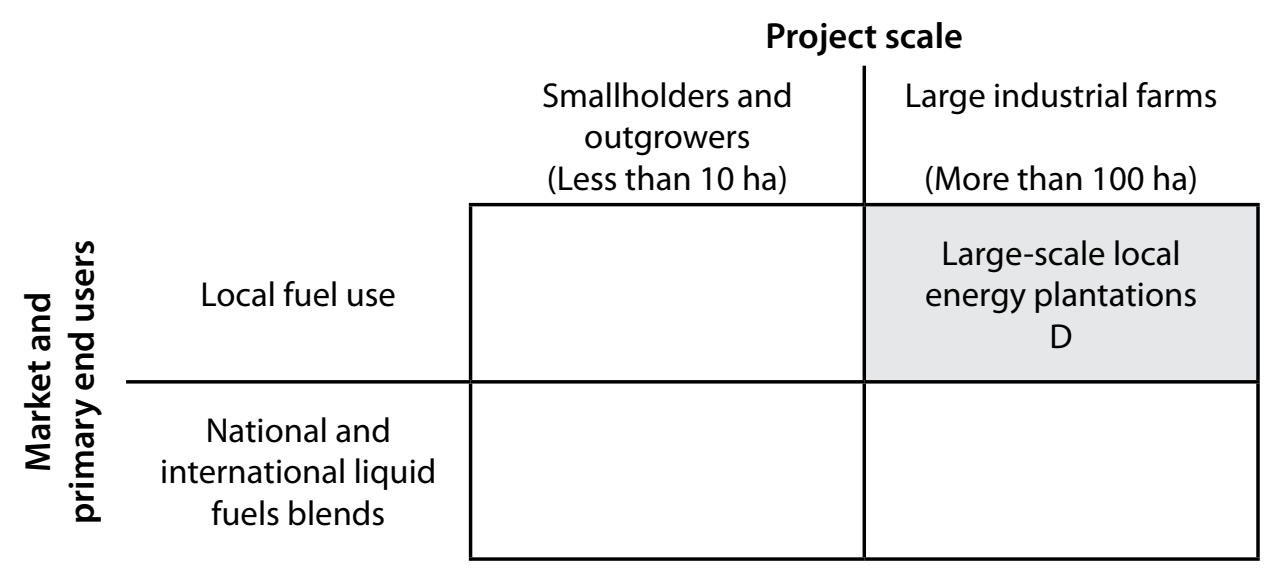

Figure 5. These projects are corporate, large-scale projects that provide energy to a related corporation for local use 


\subsubsection{Constraints to establishment}

These projects have similar constraints to large-scale projects, though if the company already owned (or had usage rights to) the land then this greatly reduces the acquisition constraints. These projects could be regarded as diverting attention from the industry's core function (e.g. mining or farming) and hence not be supported by shareholders. These types of projects are expensive to set up, as they require a substantial capital commitment and feedstock crops may take a few years to mature before they become operational. Jatropha has been suggested as a possible crop for some projects of this type, however unproven yields leaves a question over jatropha's viability as a feedstock. If in the future high-yielding jatropha varieties are bred, then this model may become viable for this feedstock.

\subsubsection{Potential impacts}

These large plantations may share similar positive and negative impacts to large-scale liquid biofuel plantations:

\subsubsection{Policy options for enhanced benefits}

This model is fairly rare, and hence is currently not a priority area. No regional or national policy was found specifically in support of this model. However the issues relating to model A will be pertinent and since fuel is not destined for certified markets, the use of certification as a control would be inefficient. 


\section{Actions for achieving improved models of biofuel development}

The preceding section investigated opportunities for enhancing benefits within specific feedstock production models. It is, however, very likely that, based on national priorities such as enhanced rural development, national economic benefits can be enhanced by changing the ratio of projects within different feedstock production models. Market forces and financial viability are likely to favour a specific feedstock production model. This model may not be the most optimum model from a national development perspective. In such instances, legislation and economic incentives and disincentives are needed to shift investors into different (more nationally beneficial) biofuel feedstock production models.

\subsection{Increasing the ratio of small-scale to large-scale plantations}

Large-scale plantations are likely to be the most favoured option for international investors in the biofuel feedstock producing industry (Cushion 2010, Cotula et al. 2008). A policy decision to shift a proportion of biofuel production from large- to smallscale could be used to increase the biofuel's rural development benefits (Figure 6). This change is most relevant in projects where biofuel is being produced for the liquid transportation fuel market, but could also be used by companies seeking local fuel security. A number of countries have already put in place biofuel policies in support of this shift. For instance, in Brazil the social seal is designed to force companies to support small-scale producers (Rossi and Lambrou 2009). In South Africa the national biofuel strategy will only provide support (in terms of tax concessions and access to blended markets) to biofuel refineries where feedstock is sourced from what are termed previously disadvantaged farmers, who would effectively be mostly small-scale farmers.

\subsubsection{Potential opportunities}

It is the development of a biofuels industry with both processing mills, large-scale plantations and other supporting infrastructure (such as road networks, markets and input supplies) that creates the opportunity for developing a small-scale biofuels feedstock supply sector. Restricted access to land for large-scale plantations might, on its own, promote the large-scale sector to invest in outgrowers as has been the case in the South African forestry sector and the Malawian sugar sector (Meyers et al. 2002, ISO 2008). Processing mills often have capacity to process volumes beyond those supplied by the mills' own plantations (or large-scale plantations contractually linked to the mill). The mill is therefore often eager

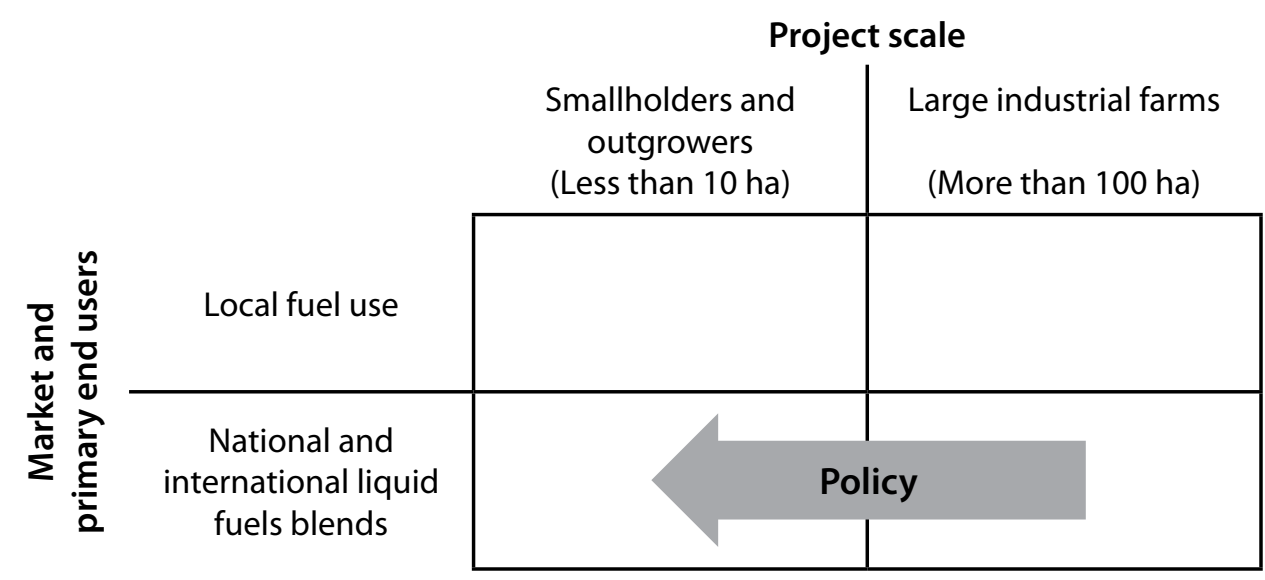

Figure 6. Use of policy interventions to change the ratio of feedstock production from large-scale to small-scale producers 
to acquire additional feedstock. Small financial incentives and/or a conducive policy environment could persuade investors to support the development of an outgrower section.

\subsubsection{Constraints to establishment}

The constraints as discussed for small-scale producers in section 5.2.2 are also relevant here. The main constraint to changing the ratio of small- to largescale producers is likely to be financial and the simplicity of business models when dealing with large plantations and the high transaction and logistic costs associated with managing large numbers of small producers. However, if the large-scale sector is restricted too much then this could suppress the development of the entire biofuel industry as it could deter investment. The optimum size of the large-scale sector is likely to differ between different fuel types and feedstocks (Hayami 2010). For instance, there are examples of developing biodiesel production models based on jatropha in Zambia where no large-scale plantations are involved; however, the long-term sustainability of this model is as yet unproven and could lead to smallholders bearing the burden of trailing an unviable feedstock (Haywood et al. 2008, German et al. 2010a).

\subsubsection{Potential impacts}

Increasing the ratio of micro and small-scale feedstock production to large-scale feedstock production carries with it all the constraints generic to the small-scale feedstock producing sector. From a policy perspective, changing the ratio has the following additional constraints:

- Market forces are likely to lead investors to largescale plantations in most circumstances (Cushion 2010, Cotula et al. 2008).

- Although small-scale biofuel production is assumed to be more socially beneficial than largescale production, a number of constraints are linked to small-scale production as listed in the small-scale production section above.

- Although there might be overall national social benefits, the government might lose out on direct tax-based finances that are more easily collected from large-scale enterprises.
- The small-scale sector is far more difficult to control or regulate. If incentives are in place to stimulate this sector, the impacts might be unpredictable as to how the sector develops, what land is used, and so forth.

- Lack of capital in the smallholder sector makes it difficult for them to invest in biofuel development (Pahariya and Mukherjee 2007).

From a national perspective, increasing the ratio of small growers to large-scale plantations has a number of positive impacts in terms of equity of ownership and the types of developmental benefits that will be achieved. African biofuel projects are too young to fully research the relative benefits from small- versus large-scale plantations, but there is a strong body of evidence that small-scale production has greater rural development benefits. But this issue is contentious because some benefits only occur from large-scale development, such as infrastructure and corporate social responsibility spending (Cushion et al. 2010, Pahariya and Mukherjee 2007, Vermeulen and Goad 2006).

\subsubsection{Options for shifting the ratios of small to large-scale plantations}

\section{Incentives to large industry to include small growers}

A number of mechanisms can be used to incentivise large industry to assist in establishing the small grower sector. These include:

- Requirement for a certain percentage of feedstock originate from small holders for eligibility for subsidies or benefits (such as access to mandatory blend markets). The social seal approach in Brazil uses this principle;

- Enforcement of contract law to reduce the risks and costs of side-selling;

- Requirements linked to land acquisition; and

- Restrictions on total land acquisition. If corporate plantations can only supply a proportion of the mill's feedstock requirements then the mill will be obliged to find alternative growers. This is in effect what has happened in the South African commercial forestry industry, where the industry has run out of land for corporate plantations due 
to government-imposed water licences (Mayers et al. 2002).

Certification requirements can be a strong mechanism for driving these behaviours as can government subsidies and taxes.

\section{Incentives to aid in establishing small growers}

Direct incentives can be given to small growers to assist in establishing themselves. These include:

- Access to extension services and technical assistance;

- Reduced costs (subsidies) on inputs such as fertilisers;

- Reduced taxes;

- Access to knowledge on production, storage and (pre-)processing;

- Capital grants to improve production and shift into more sustainable agricultural practices;

- Access to microfinancing at low interest rates; and

- Off-take and price guarantee.

These incentives are largely based on governmentfunded programmes. Certification would have limited or no impact on these mechanisms. However, if mills are required to obtain a proportion of their feedstock from small-scale growers, they are likely to create their own incentive schemes to assist small growers in establishing. Certification requirements on obtaining feedstock from small growers will therefore have this secondary impact.

\section{Banning of large plantations whilst incentivising the establishment of processing facilities}

The banning or restricting of large-scale plantations, whilst providing a favourable environment for the establishment of a biofuel processing industry, would force potential investors to establish a viable smallscale feedstock production sector if they wished to establish processing facilities. This would have the combined benefit of ensuring processing takes place in the country as well as ensuring that production is from smallholders. Though models based totally on small-scale production is quite common in the jatropha sector, these models are rare in the sugar sector where secured supply close to the processing plant is critical. Kenya, however, has about $90 \%$ of its sugar provided by small-scale farmers, proving that such a model is feasible (ISO 2008). Possible incentives to attract processing facilities could include:

- Establishment of free trade zones;

- Rapid depreciation of equipment;

- No, or reduced import tax on equipment;

- Tax incentives, including on export tax or exemptions of fuel tax on biofuels;

- Direct subsidies; and

- Guaranteed market such as through mandatory blends;

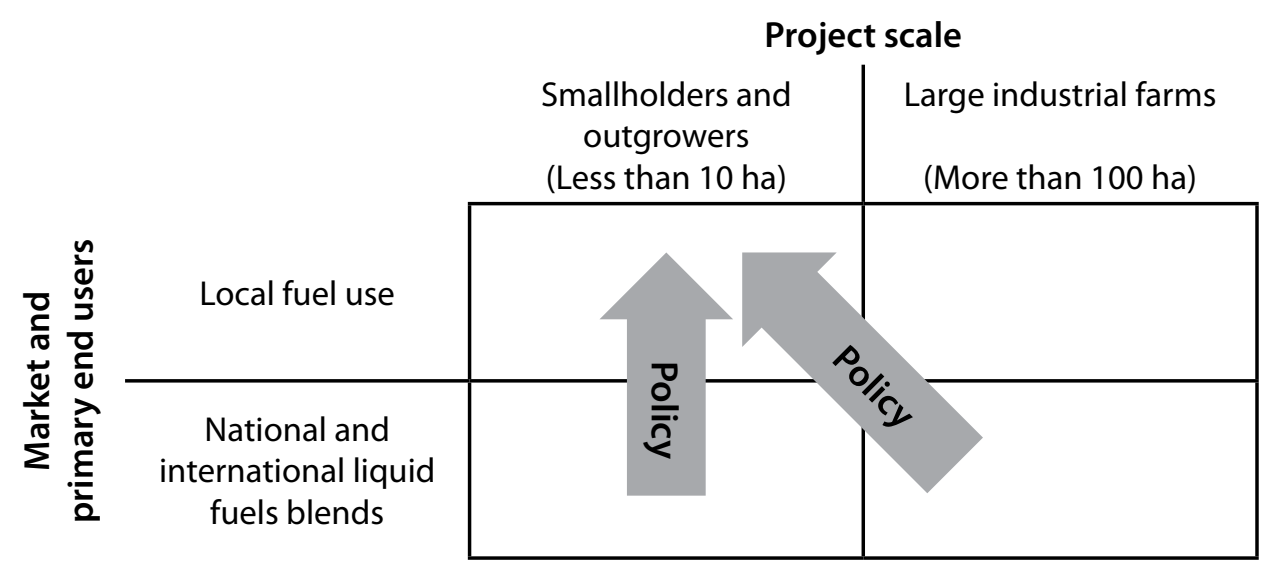

Figure 7. Use of policy interventions to stimulate biofuel projects for local energy use rather than sale to the liquid transport fuel markets 
A legislative ban on large-scale plantations would be needed as well as a package of government incentives to create a favourable investor environment for processing facilities.

\subsection{Moving from global fuel supply to local fuel security}

To stimulate rural development, and reduce rural energy poverty, a policy objective could be that a greater proportion of biofuel should be devoted to local fuel needs rather than liquid biofuel destined for national or international transportation fuel blends. In other words the policy objective would be that biofuel production must increase rural access to energy, and not just rural access to income-generating activities (Figure 7). Examples such as the FACT Foundation project in Mali have already been discussed, but there is the potential for a far wider range of benefits and operational models.

\subsubsection{Potential opportunities}

The potential to use biofuel as a mechanism for driving rural development through both job creation and allowing the rural poor to advance up what is often termed the energy ladder (UNDP 2005) will be discussed in section 5.3.2. In addition, biofuel could potentially be used as an urban fuel source, particularly as an ethanol gel with substantial positive impacts on human health when charcoal burning is a major contributor to respiratory disease (Bailis et al. 2005, Zuzarte 2007).

A second and less well explored opportunity is the potential to reduce deforestation. In the African context, deforestation has 3 main drivers, although the relative importance of each is poorly researched and situation-specific (FAO 2010, Geist and Lambin 2001). The drivers are: the use of traditional fuels, especially charcoal (which is largely for urban consumption) (World Bank 2009, Mugo and Ong 2006, Sepp 2008); legal and illegal trade in tropical hardwoods (FAO 2010, Geist and Lambin 2001); and clearing forest for agricultural fields.

Many of the drivers in Africa are related to poverty. Charcoal has very limited returns to the maker, but is a major industry because the rural poor have very limited alternative income sources (World Bank 2009, Mugo and Ong 2006, Sepp 2008) and there is high urban demand for cheap energy (Sepp 2008). Biofuels could be part of a solution for alleviating rural poverty by providing alternative livelihood opportunities, whilst simultaneously providing a cheap alternative fuel source.

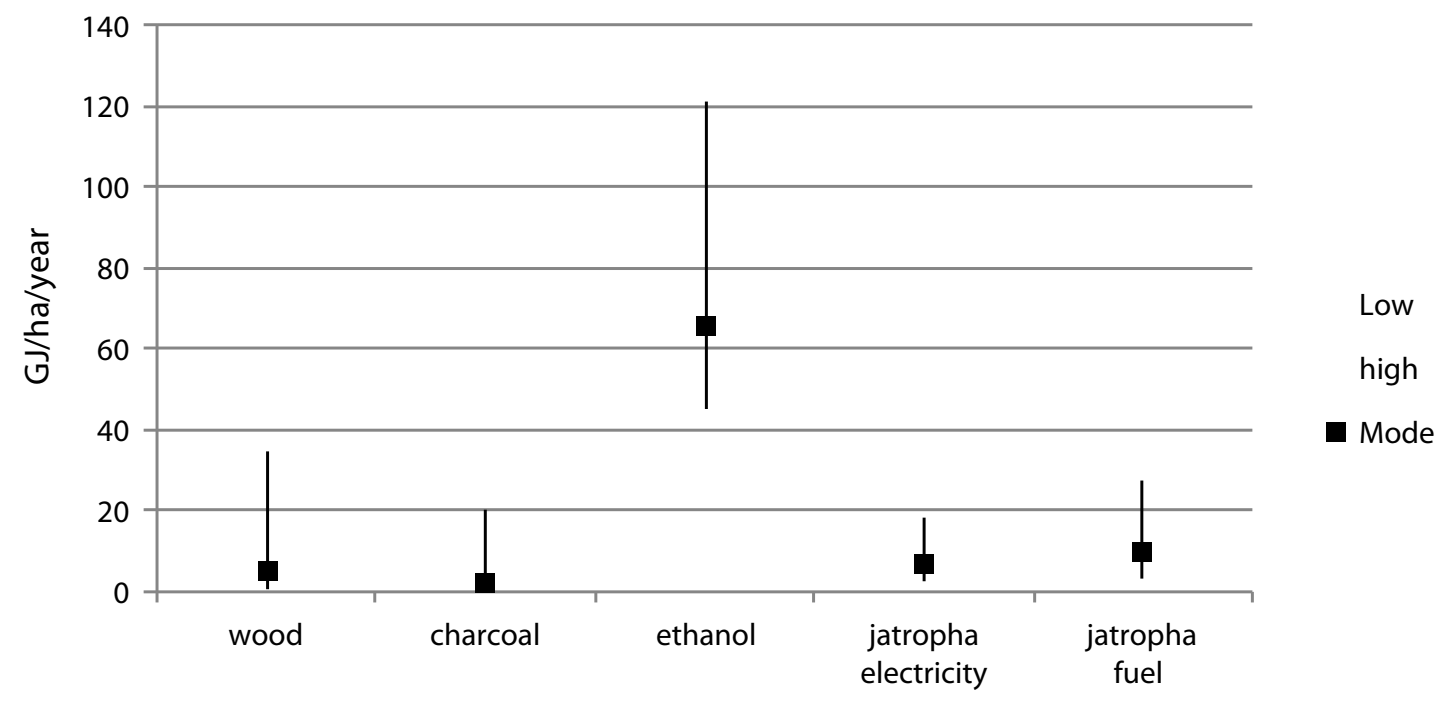

Figure 8. GJ of usable cooking energy per ha of land used to grow the feedstock based on von Maltitz and Mapako (in prep). The mode value represents likely current scenarios, with the low and high values based on both production and consumption efficiencies. 
Biofuels, in some circumstances, could require less land per unit of useful cooking energy than traditional wood and charcoal (von Maltitz and Mapako in prep). As illustrated in Figure 8, the energy efficiency of ethanol gel-based cooking fuel would require 20 to 100 times less forest land than is required for charcoal making to provide the same amount of useable energy for household cooking. However, current ethanol crops result in total clearing of forest land whereas charcoal making typically retains forest, albeit in a highly degraded state. The opportunity may therefore exist for substituting the current charcoal demand with ethanolbased fuels. The Gaia Foundation has been piloting these technologies in Brazil and Ethiopia and the Millennium Gelfuel Initiative (MGI), in Malawi and Zimbabwe, with some positive results (Schlag and Zuzarte 2008).

If biofuel can be linked to reducing deforestation then there is an opportunity for global carbon fund mechanisms such as CDM or RED+ to act as funding streams. Equally, if biofuel reduces the health risk from charcoal burning, it could be subsidised through healthrelated funding streams.

\subsubsection{Constraints to establishment}

The constraints to establishment as discussed for small-scale local energy producers in section 4.2.2 is also relevant here. An overall constraint is likely to be that this will require relatively expensive government intervention, and will require a government commitment to investing in rural and urban pro-poor development. Despite the rhetoric of the importance of rural development, governments in Africa have a low track record of prioritising rural and pro-poor investment (UNESC 2007).

If ethanol gel is to be considered as a replacement fuel for charcoal then there are numerous constraints. Bringing about a change in fuel use is not an easy exercise and would require careful facilitation as well as the correct financial and social incentives. Comparative cost and social acceptance would be a key concern, but ethanol gel has safety and human health benefits (Zuzarte 2007). In countries such as Tanzania, the charcoal industry is huge, and is a critical income generating activity for many of the rural poor (World Bank 2009), despite the fact that the producer earns very little (Sepp 2008). Numerous transporters, and retailers also make a living from charcoal, and it is this aspect that contributes mostly to the retail price. Any biofuel activity aimed at reducing charcoal-driven deforestation would have to take into consideration the vast socio-economic consequences to the rural population.

\subsubsection{Potential impacts}

Projects aimed at fuel security, reducing deforestation or improving human health tend to be driven more by development objectives rather than commercial objectives. As such there are potential impacts, as already discussed in section 4.3. Although moving energy production for local energy use into rural areas is an appealing concept, implementation is likely to be difficult and could have huge indirect socioeconomic consequences due to the importance of current fuelwood and charcoal industries to the rural poor.

These projects are largely aimed at local energy security and reducing both energy and financial poverty. These types of projects try simultaneously to meet 2 developmental goals, firstly to address rural poverty by creating new income streams and secondly to address energy poverty by creating more affordable access to modern energy sources. They are also beneficial in:

- Bringing development (beyond simply feedstock production) into rural areas by increasing local roles in the preprocessing and processing of biomass feedstock;

- Empowering local people and diversifying the local economy beyond simply agricultural production, through direct jobs linked to the energy production and secondary job opportunities due to greater energy affordability and access. For instance, electrification can power a large variety of appliances such as sewing machines or welding machines to support new secondary enterprises in rural areas;

- Allowing for electrification in areas that cannot be economically reached by national power grids due to high transmission costs and/or low density energy demand in the rural areas;

- Potentially reducing deforestation through a shift away from traditional energy such as firewood and charcoal (von Maltitz and Mapako in prep);

- Biomass gasification technology from sustainably produced feedstock being environment-friendly, 
because of the firewood savings and reduction in $\mathrm{CO}_{2}$ emissions; and

- Moving fuel away from charcoal to biofuels, which may have human health benefits since most biofuels produce less particulates when burnt than wood and charcoal (Bailis et al. 2005).

These types of changes will require policy intervention and government and donor support. Projects are unlikely to be led by the private sector. Some form of subsidy is likely to be required to make these projects viable, but this is easily justified by the rural development benefits. Subsidies or payments for ecosystem services may also be appropriate if a direct positive link can be shown between the projects and reduced rates of biodiversity loss and deforestation.

\subsubsection{Options for enhancing opportunities for domestic energy from biofuels}

\section{Modernisation of traditional biomass-to-energy production and use}

The realisation is emerging that different energy needs are required for modern services (such as modern communication, cooking, and transport) and that these are unlikely to be met by a single energy carrier. A pertinent example is that access to electricity does not imply that it will be used for all services - many poor Africans continue to use firewood or paraffin for cooking despite having access to electricity, simply because they are more affordable and often only carry the cost of labour. Additionally, there may be social or secondary benefits from traditional firewood use for cooking compared to using electricity such as the heat (warmth), taste and ambience. Therefore, the greatest intervention may be introducing more efficient stoves. Secondary to this, opportunities to replace traditional biomass should be explored.

\section{Ethanol gel as a replacement for charcoal or kerosene for low income cooking fuels}

A gel made from ethanol and a starch (for gelling) can provide a viable alternative to fuels such as charcoal or paraffin as a low income cooking fuel (Zuzarte 2007). The gel is inexpensive to make (with the key cost being the ethanol) and it can be burnt in efficient, but relatively affordable stoves. The gel poses less of a fire risk than kerosene, and is cleaner burning than either paraffin of charcoal, greatly reducing the health impacts from indoor cooking (Silversands 2010, Mengesha 2011, Zuzarte 2007). However, ethanol gel has a lower heating value compared to kerosene which means that you use more to do the same job. To be meaningful, the comparison should use energy return on investment or the comparable cost to cook a meal, rather than a simple comparison on cost per volume. Currently ethanol costs are comparable with kerosene, and are more than for charcoal, although this is obviously very much situation-specific (Zuzarte 2007). The production of ethanol gel has 2 approaches. It could be a coproduct from large-scale ethanol plants, (i.e. a proportion of ethanol produced could be diverted to the cooking fuel market), or small-scale ethanol producing facilities could be set up specifically to produce ethanol for the stove market. Experience in Brazil, Tanzania and Ethiopia and South Africa's Silversands project have shown that small-scale ethanol production is technically and economically feasible (Zuzarte 2007, Amigun and Blottnitz 2009, Mengesha 2011). However, the ethanol gel made by Silversands is subsidised by the South African Government's free basic energy grant as it would not be economically viable at current paraffin prices. In other African countries where the gel would need to compete against charcoal, similar subsidies might be needed to make ethanol gel viable. These could be justifiable on the basis of improved health, reduced deforestation and improved safety

\section{Production of transportation fuels for local use}

This model starts to merge between local energy and the production of transport fuel. The fuel is, however, not destined for national or international fuel blending, but rather is used locally for local needs. Use of $100 \%$ biodiesel or even straight vegetable oil can directly replace fossil diesel in many diesel engines. Older and less complex engines, providing they have no rubber seals, can easily use biofuels. Most modern diesel engines can run on biodiesel provided the quality is reasonable. It is technically feasible for a rural community to produce their own fuels for trucks and tractors, and hence make extensive savings on fuel purchases. This does, however, depend on the fuel source, as the Bilibiza FACT Foundation project in Mozambique indicates that fuel quality is highly variable between one microfarmer and another and poor quality oil can 
destroy diesel engines. A quality control process would therefore have to be in place. Many rural areas pay a premium on diesel due to transportation costs. In a country such as Zambia where diesel prices are already high, the areas far from the main cities pay even higher costs. Small-scale biodiesel plants that are able to maintain an acceptable fuel quality are reasonably inexpensive and reasonably simple to operate. Human capacity and financing are likely to be key constraints to establishing such industries, but the potential benefits could be substantial.

Although the use of ethanol as a fuel is technically more challenging than biodiesel, new technologies are being developed and tested to use ethanol as a direct petrol and diesel replacement. Using fully ethanol compliant cars rather than mixing ethanol and petrol has the advantage that less expensive 95\% pure ethanol can be used (to mix ethanol with petrol requires ethanol of about $99 \%$ purity, but removing this last $4 \%$ of water is a costly and energy intensive process). New technologies are being piloted that, through the use of additives and engine modifications, enable diesel engines to use ethanol as the energy source (Scania 2007).

An attractive option is that if communities can produce more fuel than is consumed locally then the surplus could be sold, bringing an additional direct revenue stream to the area.

\section{Use of gasification for electricity}

Gasification may be a more economic model for electricity generation than the use of jatropha oil. Although technically a more complex process, this efficiency is likely to be better in terms of labour requirements, and land needed per $\mathrm{kWh}$. Power stations could potentially be large enough to sell surplus power back to the national power utility or to local institutions (such as hospitals) that currently depend on diesel generators. Dedicated plantations with short rotation, fast-growing trees would provide the fuel (see Buchholz and Volk 2007, Buchholz et al. 2007a and 2007b, Buchholz and Volk 2011).

\section{Promotion of energy self-sufficiency and multifunctional platforms}

Biofuels provide a mechanism for bringing modern fuels to rural areas in a way that provides local income opportunities rather than encouraging village money be spent on external inputs, namely fossil fuel. The projects could include dedicated electricity development as in Mali, or multifunctional platforms as in Tanzania. These projects have multiple developmental impacts that include new job opportunities from growing biofuels, new opportunities made possible due to electrification, better light in the homesteads which allows for nighttime activities such as reading and studying, and access to mechanical power for pumping, milling and other activities. Costs that community members bore in the past for purchasing inefficient lighting sources such as candles and paraffin lamps may be sufficient to fund new and improved electrical lights. Electricity in these projects will, however, not replace traditional fuels for cooking as the supply is not sufficient.

Promotion of projects of this nature will require extensive government and donor funding and, though the actual operating costs may be self-sustaining, it is likely that the initial capital costs will need subsidisation. The costs to the state may well be less than the costs of providing grid electricity.

An additional benefit of these types of projects is that they may build local capacity in the management of community level power utilities.

\subsection{Developing a small-scale farming sector}

Although a lot of literature supports enhancing livelihood opportunities for microscale farmers (i.e. those small-scale and largely subsistence farmers with access to only a few hectares of land) (Rossi and Lambrou 2009, Cushion et al. 2010), an argument can also be made for assisting in the establishment of a class of commercial farmers undertaking commercial farming on economically viable small to medium scale farms (possibly ranging in size from 10 to a few hundred hectares), in other words, assisting farmers to move from functional subsistence to farming for profit on small- to medium-size commercial farms. This commercial model is found throughout most of 
the developed world and in a number of developing countries. It has also been used in establishing a successful sugar industry in Kenya and Tanzania. The distinction between microgrowers and small- to medium-scale farmers is blurred, but would largely relate to a movement from subsistence to commercial farming. This objective of developing small-scale farmers can be achieved in 2 ways:

- assisting microscale farmers to increase their farming area and improve their farming practices so that they become independent commercial farmers; and

- breaking up large-scale corporate owned plantations into numerous smaller privately owned plantations (Figure 9).

D1 Oils in their original expansion plans for Zambia considered a mixed model of microfarms, small commercial farms and large-scale corporate plantations (D1 never fully implemented this and has largely disinvested from southern Africa) (D1 2007).

\subsubsection{Potential opportunities}

The investor interest and industry support linked to biofuel developments provides a unique opportunity for establishing a commercial farming class. In many instances the industry and its investors are prepared to facilitate and fund a process of opening up new land for medium-scale feedstock producing farms.

\subsubsection{Constraints to establishment}

On very small farms, production of household food may be a better land use option than production of a relatively low valued biofuel crop. To become a commercial biofuel producer, the small-scale farmer will need sufficient land to make a reasonable living off their biofuel production, potentially still having some land left over for food production. Land tenure remains a key constraint in many African countries, making land acquisition difficult. This constraint deters people from investing in land and, in particular, from adopting perennial crops such as jatropha and oil palm. Lack of skills and capacity amongst potential farmers as well as lack of finance, since land can often not be used as collateral, for farmers are also potential constraints. Community infighting, corruption, patronage, protectionism, buyer-led markets, HIV and climate change can also place major constraints on the establishment of these project types, and can lead to long-term instability (Valentino 2011). Funding also remains a constraint. Whilst large-scale plantations my be able to raise capital from investors through international stock exchanges, , it is harder for small-scale farmers to access this international capital. Even local capital my be hard to access for potential farmers.

\subsubsection{Potential impacts}

Moving biofuel production from microfarmers or plantations to small-scale, privately owned commercial farms carries a number of potential negative impacts, including most of the impacts common to large-scale biofuel plantation development. The advantage is that most land is going to national rather than international farmers, with farming profit being retained by the national farmers. These types of projects are just as likely to displace existing land use as are large-scale plantations. However, due to constraints on time and labour,

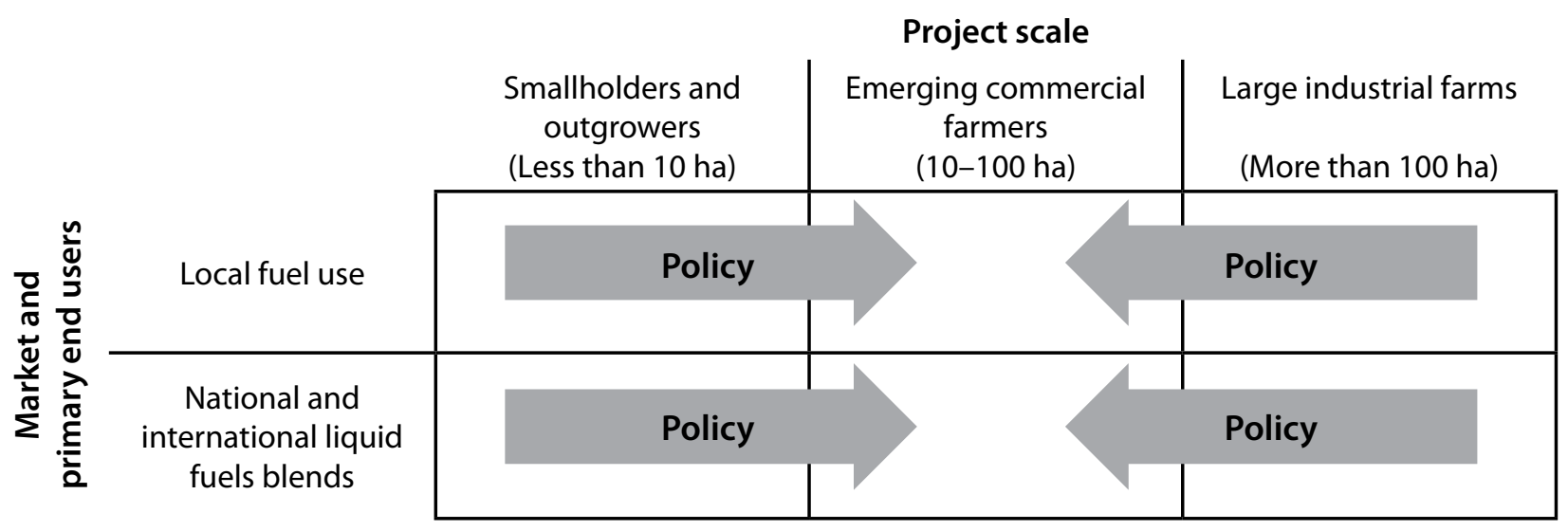

Figure 9. Use of policy to use biofuel to stimulate the development of small- to medium-scale farmers 
food crops will likely be more directly displaced in the long run for cash crops, potentially having more detrimental effects on long-term food security. Regulation of farming practice, including labour practice is likely to be far more difficult on these medium-scale farms than on corporate plantations, but easier than on subsistence farms.

\subsubsection{Options for developing a small-scale commercial farming sector}

Land size is a constraint to development of a more market-orientated commercial small-scale farming sector based on the production of biofuel crops. There is good evidence that there is a link between farmer performance and land size within the African small-scale farming sector, with almost all surplus originating from the fourth quartile of farmers, those who on average have the largest farms (Wiggins 2009). In some projects, including many historic sugar production projects, new irrigated land is made available to farmers, adding new fields, rather than replacing existing fields. This is obviously only possible where land is available and will displace noncrop-based land use such as grazing. Though the land size required to be commercially viable is situation dependent, it is likely that the development of a commercially viable biofuels feedstock sector based on the small-grower model will require that the small growers have access to a reasonable amount of land.

Land tenure and rules over land ownership may be constraints to reforms in the agricultural sector, and in some cases may be a perverse incentive allowing large-scale foreign investors access, but restricting access by local framers. A tenure system that allows for farm expansion of local farmers may therefore be needed wherever the existing system inhibits this. Reviewing tenure legislation may be an appropriate mechanism to empower farmers to expand their farming activities. In addition financial constraints often inhibit agricultural expansion. This may be linked to land tenure, because in countries with communal tenure it is not possible to use land as security against loans. However, establishing suitable agricultural loan facilities may overcome this obstacle.

State support could facilitate the development of the sector in a number of ways including provision of infrastructure such as roads and irrigation, reducing taxation on both produce and inputs, providing appropriate research, facilitating land acquisition and assisting in access to loans.

Managing a commercial farm requires numerous skills beyond the agricultural skills of subsistence farmers. These would include financial management, labour management and machinery management as well as different agronomy practices from those used at the small-scale. Developing agricultural capacities through the provision of appropriate extension and training services would therefore be an important intervention to enabling the growth of a small-scale farming sector. Linking this to appropriate research may also boost the potential farmer performance. In house research is being undertaken by many of the large biofuel producers such a D1 and Sun Biofuels. The small-scale farmers cannot afford this $r$ esearch and may well require research assistance from the state or biofuels industry.

Facilitating an environment where strong links can be build between the small growers and the biofuel industry (including large-scale plantations where they occur) can greatly help capacitate the small-scale farmers. The biofuel industry can also play a critical role in providing a guaranteed market. There is a huge opportunity for partnerships between biofuel investors and small-scale farmers. Joint ventures of various forms could be formed which lead to a winwin situation between the biofuels investors and the farmers. Certainly there might be a number of short term obstacles to establish a reliable feedstock stream from predominantly small-scale farmers, but if well managed this might lead to better long term sustainability.

One option is that where an investor would have originally set up a large commercially owned farm, this is instead divided into a large number of small and locally owned private farms. These could potentially be farmed as a large cooperative scheme so as to still gain the scale advantages of a large farm. This type of farming model is well established in the sugar industry (ISO 2008).

Market access is typically an important constraint to agricultural development in Africa. In this sense biofuels may have an advantage over food crops as the biofuel sector can create a strong market pull. However, if blending targets are reached (nationally and/or internationally) then this may 
have a downward pressure on biofuel prices and farm profitability. Despite this potential long term concern, the fact that a mill can only operate profitably if it has access to sufficient feedstock provides a strong motive for the mill to ensure that the farmers providing the feedstock remain viable (Mayer et al. 2001). Contract farming is often a mechanism used to achieve this, and contact farming is known to facilitate market linkages (Oluoch-Kosura 2010). There are many examples in the forestry and sugar industry where the processing mills provide extensive assistance to ensure a viable small-scale farming sector. Mechanisms such as the Brazilian social seal can also be used as additional incentive to the mills to ensure the inclusion of small-scale farmers. 


\section{Large-scale versus small-scale processing facilities}

The preceding sections have focused on the feedstock production side of the biofuel chain, as this is where the most extensive land use change will take place and where the greatest number of job opportunities will be created. In addition, the feedstock production aspect of biofuels is where the greatest activity in SSA has taken place to date, with many projects having no processing facility, or in some cases the feedstock being directly exported in unprocessed or partly processed form (e.g. as plant oil). This means that there is very limited SSA experience in biofuel production that can be drawn upon. Studies have, however, looked at theoretical aspects of biofuel processing, and general principles can also be learned from the experience in other parts of the world.

The size and location of biofuel processing facilities can have profound impacts on a biofuel programme's development. In general, market forces are likely to lead to centralised, large-scale processing facilities located close to major cities and ports. Incentivising the decentralising of processing facilities and the creation of smaller facilities can potentially enhance rural development opportunities. However, a number of trade-offs are involved.

\subsection{Opportunities from small-scale biofuel processing facilities}

Promoting the development small-scale biofuel refineries rather than large-scale projects could potentially have positive benefits that are in line with SSA's desired outcomes from engaging in biofuel development. These include:

- Can be rural-based, thereby growing the rural economy.

- Can potentially bring cheaper fuel into deeply rural areas.

- Increased value adding in the feedstock producing area and hence greater economic benefits to the rural areas.
- Increased equity of ownership since local investors can more easily establish small-scale rather than large-scale processing plants. It also increases the potential for far higher levels of national ownership in the biofuel sector.

- Increased options for tighter links between the farmer and the biofuel producer. For instance, in the case of jatropha, farmers could retain their rights to the seedcake after oil extraction, and then use this as a fertiliser either to enhance their food or fuel crop production.

- The possibility that providing local fuels can help reduce the rates of deforestation, as discussed in section 6.2.

- A better greenhouse gas balance due to reduced transport (although this might have to be offset against lower efficiency and lower opportunity for cogeneration).

- Increased opportunity for biofuel feedstock production in areas that would be too remote to service centralised processing facilities. Transporting a refined fuel is easier than transporting bulky and heavy feedstock and the energy density of final fuel is typically higher than for the feedstock.

Policy to promote small-scale fuel production would need to provide both financial and technical support to start the small-scale processing sector. Legislative changes to existing petroleum legislation may also be needed.

\subsection{Constraints to the establishment of small-scale biofuel processing}

Creating biofuel processing at the local level will be a challenging task as a number of constraints would need to be overcome, such as:

- Economies of scale (as discussed in more detail below) mean that the capital and operational costs 
are greater for smaller plants, which can reduce total profits.

- Technical capacity to manage the production facilities (as discussed in more detail below) is a national constraint in many SSA countries, and is particularly acute in rural areas.

- Investors, especially foreign investors, are most likely to invest in large-scale processing plants linked to export markets, as this is where they are most likely to have low market risk and high returns.

- Small processing plants located in the rural environment will be far from blending facilities if blending is envisaged. This is especially relevant to ethanol which is currently only useful as a formal blend since there are few modified ethanol engines. In the case of diesel, informal blending in any ratio is possible, but for petrol a controlled process is required when the ethanol substitutes for other additives.

- Prohibitive sunk costs of constructing a processing plant; lack of access to cheap financial capital.

- Low purchasing power in rural areas (however, it must be pointed out that many rural areas already spend large amounts on diesel).

- Motor manufacturers may not provide warranties for vehicles operating on biofuels. This may be a relatively minor issue for rural areas where most of the vehicle fleet is old and outside the warranty period. Some tractor manufacturers are providing warranties for $100 \%$ biodiesel usage.

- Rural farms may be far from ports so that transportation costs to biofuels markets are considerable. However, fuels should be more easily transportable than biomass feedstock.

\subsubsection{Economies of scale}

Biodiesel plants can theoretically be any size with planned units ranging from a few hundred litres per day up to 15 million litres per day. Excluding the very small plants, economies of scale are very weak, and therefore the driver for large plants is relatively weak from an economic perspective. Amigun et al. (2008), for instance, found that optimum size can range from 500 to $5000 \mathrm{~kg} / \mathrm{h}$ with a near flat profile around optimum plant size. Possibly a greater scale-dependent criteria is the move from manual crushing for oil extraction to chemical oil extraction which is far more efficient, but only viable for large-scale processing plants (Achten et al. 2008). A further consideration is the use of continuous flow plants versus batch flow plants, with continuous flow typically being viable at larger sizes, although new microprocessor continuous flow plants are currently being developed (Buddoo et al. 2008). The fact that feedstock (oilseeds) are relatively concentrated and dense means that transportation distance is not as critical in the economics of biodiesel production compared to ethanol production where the feedstock (sugary and starchy plants) is bulkier.

In contrast, bioethanol plants tend to show strong economies of scale, and this has favoured large-scale processing facilities. The need to be close to feedstock supplies and the cost of feedstock transportation provides a competing economic incentive and smaller processing facilities may be more economic in areas with low agricultural yields (Amigun et al. 2008). Moving from $95 \%$ pure ethanol (which can be used in special ethanol cars) to $99 \%$ pure ethanol (as is needed for petroleum blends) is also only feasible in larger scale plants, unless the initial production, processing and distillation is done by distributed small-scale operators and the upgrading to pure (99\%) ethanol at large, centralised ethanol plants.

Small-scale ethanol plants, though more complex than biodiesel plants, are technically feasible, and a number are found in practice, although these tend not to be aimed at the liquid fuel market. In its simplest form an ethanol plant is no different from traditional stills used to distil alcohol as a beverage. Although these plants are probably not competitive with liquid biofuel markets, they can provide niche fuel products for local use, as demonstrated by the Gaia pilot projects in Brazil and Ethiopia or by the Silversands project in South Africa (Silversands 2010, Mengesha 2011, GAIA 2010, Zuzarte 2007).

\subsubsection{Technical and quality challenges}

Large-scale batch processing biodiesel plants are technically complex systems although they are well established and turnkey installations are readily available. This could pose a challenge to deeply rural areas without the technical capacity to ensure the plant is run efficiently. Even simple, low-volume, 
batch processing plants need some technical expertise if fuel quality is to be guaranteed. Robust machinery well suited to a rural environment and able to produce quality fuel is, however, currently feasible.

Large bioethanol refineries would need extensive technical competence and in many African situations this may require at least the initial reliance on imported labour. Even small-scale plants would need a fair degree of technical competence, although this should be available nationally in most African countries. If $99 \%$ pure ethanol is to be produced for blending, high quality standards would have to be maintained. Lower grade ethanol of $95 \%$ purity for modified ethanol engines or ethanol stoves will not require as high a level of quality standards and is more suited to small-scale producers and distillers.

Large-scale biofuel plants are likely to be the norm unless there is policy intervention to incentivise small-scale plants. There are, however, a number of benefits that might be gained from smaller and more rural processing facilities. 


\section{Conclusions}

Biofuel expansion in Africa is relatively new, and with a few exceptions, is still in its infancy. This makes it difficult to provide a detailed assessment of the opportunities and constraints based on specific data on operational projects; when available, most case study data applies more to the piloting and establishment phase of projects rather than to operational phases. Some conclusions can, however, be inferred from well-established agricultural production of feedstock crops that might be considered for the biofuel sector, thus not constraining the analysis to biofuel projects. Our analysis provides an overall assessment of these opportunities and constraints based on a nationallevel approach, hence assessing the benefits and implications from different production schemes relating to a set of desirable outcomes. In addition, it assesses potential policy options to remove barriers and enhance benefits, and recommends processes that could stimulate sustainable biofuel development.

Four areas where biofuels developments can have positive impacts are identified from SSA policy dialogue. These relate to the rural development potential from biofuels, the energy security potential, the ability to attract appropriate investment and the need for sustainable land use. The need to use biofuel investment to drive rural development is a clear message from all African policy dialogues on biofuel, and it is often embedded in the emerging national bioenergy policy, when they have been formulated. Still, a growing body of literature identifies numerous potential negative impacts on rural communities and the environment, so any proposed project would need to investigate strategically both the positive and negative impacts to ensure that biofuels production contributes toward the countries' development goals. SSA countries should aim to maximise the rural development opportunities from biofuel since it would be counterproductive as well as ethically and morally wrong if biofuels were used for national economic development and national fuel security, whilst leading to increasing poverty within communities in the affected rural areas.

Furthermore, biofuel development presents an opportunity to increase both national and local level fuel security. At the national level, domestically produced biofuels can reduce foreign exchange expenditure on imported fuel whilst simultaneously creating jobs. Alternatively, biofuel can also be used as a mechanism to bring modern fuels and energy services to remote rural areas. Biofuels could also be used to reduce deforestation by providing greater amounts of useable energy per hectare of land used than is obtained from traditional biomass fuels such as charcoal. In addition, biofuels can attract substantial amounts of direct foreign investment to SSA countries, but this investment does not automatically contribute to the objectives of rural development and local and national fuel security. Such investment may instead result in production schemes that concentrate the benefits, with most financial benefits leaving the country. Thus, it is important to ensure that these investments bring benefits for both the investor and the receiving national economies. Supporting policies should aim to ensure that as much as possible of the investment remains within the country, and that it contributes toward sustainable development, such as creating many good quality jobs. Investment that leads to growing feedstock on large, mechanised farms, and then exports the raw feedstock with almost no value adding or economic benefit to the country, should be actively discouraged.

This working paper moves forward the analysis about the opportunities and constraints of biofuel development, and likely policy choices to enhancing the former and overcoming the latter, by assessing them related to 4 distinct types of biofuel feedstock farming models. 
Large-scale plantations dedicated to producing feedstock for liquid transport fuel blends are the most common and potentially the most contentious form of biofuel production, especially where the biofuel is aimed at export markets. Although these projects bring direct foreign investment, they also have the potential for extensive negative social and environmental impacts. Many options are available to reduce potential impacts and to broaden the national benefits gained. Ensuring that current land users - including those with informal tenure rights - are not disadvantaged is critical; this needs to include the rural poor, women and children who are typically the last to benefit from new developments. Increasing the level of local ownership and involving the local community as true partners with true equity in the venture is also an option. Careful planning to minimise deforestation and biodiversity loss are also needed and will require national strategic biodiversity and forestry policies. Strategies are also needed to reduce potential food versus fuel conflicts, but it may be possible to develop a synergistic relationship between biofuel and food where biofuel development helps stimulate food production, largely through improved efficiency of resource use and intensification of agriculture. Large-scale plantations may also assist in establishing a vibrant, small-scale, biofuel feedstock producing sector.

Small or medium-scale farms producing feedstock for liquid transport fuel blends appear to have significant benefits over large-scale, mono-cropped plantations, but this needs to be carefully assessed on a case by case basis, since many more financial, market and technical barriers are working against small-scale farming, and the outcomes are more difficult to monitor than for large-scale farmers. Exploitation within the small-scale farming sector is also possible. The issue is not whether the industry should be large-scale or small-scale, but rather the appropriate ratio of small-scale to large-scale producers. At present, the processing infrastructure for large-scale biofuel plants is not yet in place in SSA, so small- to medium-scale, decentralised biofuel processing plants could therefore be a feasible option for encouraging development in Africa, since it would keep more resources and revenue within rural communities. This development of smaller scale distributed facilities is unlikely to take place unless a policy environment is in place to make this type of development more attractive than large-scale plantations.

Biofuel production to meet local energy needs is an alternate model of biofuel production for transport fuel blends. Currently a small-scale producer model is being promoted in some countries where jatropha oil is used for electricity generation or to run machinery in multifunctional platforms. This model helps develop remote rural areas through access to modern energy whilst simultaneously bringing the opportunities of new biofuel crops to local farmers. Nonetheless, given that this model of biofuel production is not driven by corporate business interests and is thus not linked to largescale investments, it is therefore likely to require extensive government or NGO involvement to make it operational.

The fourth model is biofuel feedstock production to meet the local energy needs of large-scale ruralbased corporations. This model is rare and likely to remain so, despite the fact that it might be financially viable due to the disproportionally high costs and low levels of energy access and reliability in many rural areas in SSA.

Policy interventions can be used to promote the transition toward more equitable and sustainable biofuel development schemes. This can be done by shifting the ratio of biofuel feedstock produced by different production models. Increasing the ratio of small-scale to large-scale farms is one mechanism to increase equity of ownership and to empower farmers in the rural areas. In addition, policy could encourage the creation of larger farm sizes in the smallholder sector and hence assist in moving farmers from predominantly subsistence to more market-based livelihoods. Incentivising a shift to the use of biofuel from transport to household cooking could potentially have health benefits and assist in avoiding deforestation, but this requires additional investigation and assessment in order to better understand the impacts.

A number of policy interventions are available to shift biofuel investment in the direction most beneficial to the country's desired development. Actual mechanisms will be country and situation 
specific, because the impact of biofuel production is context-specific and will vary according to feedstock, technology and the peculiarities of the country and its development goals. A balance is therefore needed between policies that will derive the greatest benefits for the country, reduce poverty and improve rural development with policies that will attract commercial investors. Though market-based mechanisms can assist in achieving the policy objectives of project linked to transportation fuel blends, these benefits are dependent on suitable national policy and financial incentives being in place.

The analysis undertaken here suggests that, left to market forces alone, it is likely that biofuel expansion will optimise financial returns to the investor, rather than meeting the strategic developmental needs of the SSA countries. Policy interventions are therefore needed to ensure that national benefits are optimised. Market-based certification processes can partly increase the sustainability of biofuel production, but these processes on their own are unlikely to ensure that biofuel will meet national strategic objectives. National strategic planning and the use of legislative and fiscal mechanisms are needed to ensure that biofuel development takes place in the most beneficial manner to the nation and its people. Once the correct policy framework is in place, for example, including the right balance of incentives and disincentives, certification may help ensure adherence to national policy. 


\section{References}

Achten, W.M.J., Verchot, L., Franken, Y.J., Mathijs, E., Singh, V.P., Aerts, R., Muys, B. 2008 Jatropha bio-diesel production and use. Biomass and Bioenergy 32(12): 1063-1084.

Actionaid 2010 Meals per gallon: the impact of industrial biofuels on people and global hunger, February 2010. http://www.actionaid.org.uk/ doc_lib/meals_per_gallon_final.pdf (7 December 2010).

Amigun, B. and von Blottnitz, H. 2007 Investigation of scale economies for African biogas installations. Energy Conversion and Management doi:10.1016/j.enconman.2007.05.009.

Amigun, B. and von Blottnitz, H. 2009 Cost analyses and predictions for a fuel ethanol plant in a rural and landlocked African country: Lang factor approach. International Journal of Production Economics 119(1): 207-216.

Amigun. B. and von Blottnitz, H. 2010 Capacity-cost and location-cost analyses for biogas plants in Africa. Resources, Conservation amd Recycling 5: 63-73.

Amigun, B., Muller-Langer, F. and von Blottnitz, H. 2008 Predicting the costs of biodiesel production in Africa: learning from Germany. Energy for Sustainable Development 12(1): 5-21.

Amigun, B., Musango, J.K. and Brent A.C. 2011 Community perspectives on the introduction of biodiesel production in the Eastern Cape province of South Africa: questionnaire survey results. Energy doi: 10.1016/j.energy.2011.01.042.

Amigun, B., Sigamoney, R., von Blottnitz, H. 2006 Commercialization of biofuel industry in Africa: a review. Renewable and Sustainable Energy Reviews. doi:10.1016/j.rser.2006.10.019.

Arndt, C., Benfica, R., Thurlow, J. and Uaiene, R. 2008 Biofuels, poverty, and growth: a computable general equilibrium analysis of Mozambique. IFPRI Discussion Paper 00803. International Food Policy Research Institute, Washington, DC.

Arndt, C., Benfica, R., Tarp. F., Thurlow, J. and Uaiene, R. 2009 Biofuels, poverty, and growth: a computable general equilibrium analysis of Mozambique. Paper presented at the International Association of Agricultural Economists Conference, Beijing, China, 16-22 August.

Arnold, M., Köhlin, K., Persson, R. and Shepherd, G. 2003 Fuelwood revisited: what has changed in the last decade? Occasional Paper 39, CIFOR, Bogor, Indonesia.

Assad, M. 2007 The Labour Law in Brazil and its application in the sugar and alcohol sector. In: Macedo, I. (ed.) Sugar cane's energy: twelve studies on Brazilian sugar cane. Agribusiness and Its Sustainability, UNICA, Brazil, 205-213.

Bailey, R. 2008 Another Inconvenient Truth: How biofuel policies are deepening poverty and accelerating climate change. OXFAM, Oxford, UK.

Bailis, R., Ezzati, M. and Kamman, D.M. 2005 Mortality and greenhouse gas impacts of biomass and petroleum energy futures in Africa. Science 308: 98-103.

Banse, M., van Meijl, H. and Woltjier, G. 2008 Consequences of EU biofuel policies on agricultural production and land use. Choices 2008 23(3): 22-7.

Batidzirai, B., Faaij, A. and Smeets, E. 2006 Biomass and bioenergy supply from Mozambique, Energy for Sustainable Development 10(1): 54-81.

Bazzani, G.M. 2005 A decision support for an integrated multi-scale analysis of irrigation: DSIRR. Journal of Environmental Management 77: 301-314.

Bell, M.L., Hobbs, B.F., Elliott, E.M., Ellis, H. and Robinson, Z. 2001 An evaluation of multi-criteria methods in integrated assessment of climate policy. Multi-Criteria Decision Analysis 10: 229-256.

Bickel, U. and Dros, J.M. 2003 The impacts of soybean cultivation on Brazilian ecosystems: three case studies. Report commissioned by the WWF Forest Conversion Initiative, http://assets.panda. org/downloads/impactsofsoybean.pdf (15 November 2010). 
Bijman, J. 2008 Contract farming in developing countries: an overview. Working Paper, Department of Business Administration, Wageningen University. Wageningen, Netherlands.

Borman, G., von Maltitz, G.P., Tiwari, S. and Scholes, M. (in press) Modelling the economic returns to labour for jatropha cultivation in southern Africa and India at differential local fuel prices. Biomass and Bioenergy.

BP Statistical Review 2010 http://www.bp.com/ productlanding.do? categoryId $=6929 \&$ contentId $=7044622$ ( 2 March 2010).

Browne, P. 2009 Tanzania suspends biofuel investments. http://greeninc.blogs.nytimes. com/2009/10/14/tanzania-suspendsbiofuelsinvestments/ (1 March 2010).

Buddoo, S.R., Siyakatshana, N. and Pongoma, B. 2008 Microreactors - a marvel of modern manufacturing technology: biodiesel case study. Science real and relevant: 2nd CSIR Biennial Conference, Pretoria, South Africa, 17-18 November 2008. http://hdl.handle. net/10204/2680 (20 April 2010).

Buchholz, T. and Volk, T.A. 2007 Technology and assessment report for a $200 \mathrm{~kW}$ gasifier producing electricity in Uganda. Report to Energy Sector Grants Program (ESGP), US Agency for International Development, BIOSYRCA project, 'Designing short rotation coppice based bioenergy systems for rural communities in east Africa'.

Buchholz, T. and Volk, T.A. [in press] Considerations of project scale and sustainability of modern bioenergy systems in Uganda. Journal of Sustainable Forestry.

Buchholz, T., Volk, T., Tennigkeit T. and Da Silva, I. 2007a Electricity production from energy forests: results from a feasibility and impact scoping study in northern Uganda for a 50 MWe grid model. Proceedings 15th European Biomass Conference in Berlin, Germany, 7-11 May.

Buchholz, T., Volk, T.A. and Luzadis, V.A. 2007b A participatory systems approach to modelling social, economic, and ecological components of bioenergy. Energy Policy 35: 6084-6094.

Campbell, B. (ed.) 1996 The Miombo in transition: woodlands and welfare in Africa. CIFOR, Bogor, Indonesia.

Cashore, B., van Kooten, G.C., Vetinsky, I., Auld, G. and Affolderbach, J. 2005 Private or self- regulation? A comparative study of forest certification choices in Canada, the United States and Germany. Forest Policy and Economics 7: 35-69.

CGIAR 2008 Biofuels research in the CGIAR: A perspective from the Science Council. ftp://ftp. fao.org/docrep/fao/010/i0231e/i0231e00.pdf (21 March 2011).

Chamdimba, O. 2009 Sustainable development of biofuel in Africa. New Partnership for Africa's Development, Johannesburg, South Africa. http://www.nepad.org/system/files/Renewable\% 20Energy\%20Document-1-Oct-2009.pdf (21 January 2011).

Cushion, E., Whiteman, A. and Dieterle, G. 2010 Bioenergy development: issues and impacts for poverty and natural resource management. World Bank, Washington, DC.

Cortez, L., Regis, M., Leal, M.R.L.V. and Sinkala, T. 2010 Why biofuels are important. In: RosilloCalle, F. and Johnson, F.X. (eds) Food versus fuel. Zed Books, London and New York.

Cotula, L. 2011 Land deals in Africa: what is in the contracts? International Institute for Environment and Development, London.

Cotula, L., Dyer, N. and Vermuelen, S. 2008 Fueling exclusion? The biofuels boom and poor people $s$ access to land. FAO and IIED, Rome and London.

Cotula, L. and Leonard, R. (eds) 2010 Alternatives to land acquisitions: agricultural investment and collaborative business models, IIED/SDC/IFAD/ CTV. London/Bern/Rome/Maputo.

Cotula, L., Vermeulen, S., Leonard, R. and Keeley, J. 2009 Land grab or development opportunity? agricultural investment and international land deals in Africa, IIED, FAO and IFAD, Rome and London.

D1 2007 D1 Oils Annual report and accounts 2007. http://www.d1 plc.com/investorsReports.php (20 September 2009).

Diaz-Chavez, R. 2010 The role of biofuels in promoting socio-economic rural development. In: Rosillo-Calle, F. and Johnson, F.X. (eds) Food versus fuel. Zed Books. London and New York.

Dodgson J., Spackman, M., Pearman, A.D. and Phillips, L.D. 2000 Multi-criteria analysis: a manual. Department of the Environment, Transport and the Regions, London, http://www.odpm.gov.uk/pub/252/ MulticriteriaanalysismanualPDF1380Kb_ id1142252.pdf (19 June 2006). 
Domac, J., Richards, K. and Risovic, S. 2005 Socioeconomic drivers in implementing bioenergy projects. Biomass and Bioenergy 28: 97-106.

Eaton, C. and Shepherd, A.W. 2001 Contract farming: partnerships for growth. FAO Agricultural Services Bulletin. Food and Agriculture Organization of the United Nations, Rome.

EC 2009 directive 2009/28/EC. On the promotion and use of energy from renewable sources and amending and subsequently repealing directives 2001/77/EC and 2003/30/EC. European Commission, Brussels, Belgium.

Energy Sector Management Assistance Programme (ESMAP) 2000 Energy services for the world's poor. World Bank, Washington, DC.

Eswaran, H., Almaraz, R., van den Berg, E. and Reich, P. 1997 An assessment of the soil resources of Africa in relation to productivity. Geoderma. 77(1): $1-18$

Fairless D. 2007 Biofuel: the little shrub that could maybe. Nature 449: 652-655.

Fold, N. 2008 Transnational sourcing practices in Ghana's perennial crop sectors. Journal of Agrarian Change 8: 94-122.

Food and Agriculture Organization (FAO) 2010 Africa's changing landscape: Securing land access for the rural poor. FAO, Rome.

Food and Agriculture Organization of the United Nations (FAO) 2008 The state of food and Agriculture. FAO, Rome.

Francis, G., Edinger, R. and Becker, K. 2005 A concept for simultaneous wasteland reclamation, fuel production, and socio-economic development in degraded areas in India: need, potential and perspectives of jatropha plantations. Natural Resources Forum 29: 12-24.

Friends of the Earth Europe 2010 Africa up for grabs: the scale and impact of land grabbing for agrifuels. Friends of the Earth Europe, Brussels, Belgium. http://www.foeeurope.org/agrofuels/ FoEE_Africa_up_for_grabs_2010.pdf

(21 March 2011).

Friis, C. and Reenberg, A. 2010 Land grab in Africa: emerging land system drivers in a teleconnected world. GLP Report No. 1. GLPIPO, Copenhagen, Denmark.

GAIA 2010 Biofuels: a failure for Africa. A briefing of the African Biodiversity Network, the Ethiopian Society for Consumer Protection and the Gaia Foundation. http://www.africanbiodiversity.org/
sites/default/files/PDFs/Biofuels\%20-\%20A\%20 Failure\%20for\%20Africa\%20(ABN,\%20Dec\%20 2010).pdf (22 February 2011).

Gallagher, E. 2008 The Gallagher review of the indirect effects of biofuels production. Renewable Fuels Agency, East Sussex, UK.

Gaunt, C.T. 2005 Meeting electrification's social objectives in South Africa, and implications for developing countries. Energy Policy 33: 1309-1317.

Geist, H.J. and Lambin E.F. 2001 What drives tropical deforestation: A meta-analysis of proximate and underlying causes of deforestation based on a subnational case study evidence. LUCC report series no4. http://www.pikpotsdam.de/members/ cramer/ teaching/0607/Geist_2001_LUCC_Report. pdf (21 March 2011).

German, L. Schoneveld, G.C. and Gumbo, D. 2010a The local social and environmental impacts of large-scale investments in biofuels in Zambia. Report prepared as part of the European Community Contribution Agreement EuropeAid/ ENV/2007/143936/TPS. CIFOR, Bogor, Indonesia.

German, L., Schoneveld, G., Skutsch, M., Andriani, R., Obidzinski, K., Pacheco, P., Komarudin, H., Andrianto, A., Lima M. and Dayang Norwana, A.A.B. 2010b The local social and environmental impacts of biofuel feedstock expansion: a synthesis of case studies from Asia, Africa and Latin America. Infobrief No. 34. 12p. CIFOR, Bogor, Indonesia.

GEXSI 2008 Jatropha biofuel 2006-2008. GEXSI LLP, Berlin, Germany.

Gordon-Maclean, A., Laizer, J., Harrison P.J. and Shemdoe, R. 2008 Biofuel industry study, Tanzania. World Wide Fund for Nature (WWF), Tanzania and Sweden.

Government of Mozambique (GoM) 2008 Mozambique biofuels assessment. Maputo, Ministry of Energy and Ministry of Agriculture, final report, 1 May.

Graham, A., Aubry, S., Künnemann R. and Suárez, M.S. 2010 CSO monitoring 2009-2010 Advancing African Agriculture (AAA): The impact of Europe's policies and practices on African agriculture and food security. Land grab study. http://www. europafrica.info

(21 March 2011).

Greenenergy 2008 Jatropha: a Greenenergy perspective. http://www.greenergy.com/Views/ perspectives/ Jatropha_full.pdf (21 March 2011).

Harrison, J.A., von Maltitz, G.P., Haywood, L, Sugrue, J.A., Diaz-Chavez, R.A. and Amezaga, J.M. 
2010a Mechanisms for driving sustainability of biofuels in developing countries. Renewable Energy Law and Policy Review 2: 197-212.

Harrison, J.A., Amezaga J.M. and von Maltitz G.P. 2010b Introduction to sustainable bioenergy for developing countries. In: Amezaga J. M., von Maltitz, G.P. and Boyes S.L. (eds) Assesing the sustainability of biofuel projects in developing countries: a framework for policy evaluation. Newcastle University, Newcastle on Tyne, UK.

Haywood, L., von Maltitz G., Setzkorn, K. and Ngepah, N. 2008 Biofuel production in South Africa, Mozambique, Malawi and Zambia: A status quo analysis of the social, economic and biophysical elements of the biofuel industry in Southern Africa. CSIR Oxfam draft report for comment. Natural Resources and the Environment, CSIR, Pretoria, South Africa

Haywood, L., de Wet, B. and von Maltitz, G.P. 2010 Planning for sustainability for bioenergy programmes, plans and projects. In: Amezaga J.M., von Maltitz, G.P. and Boyes S.L. (eds) Assessing the sustainability of biofuel projects in developing countries. a framework for policy evaluation. Newcastle University, Newcastle on Tyne, UK.

Heidhues, F., Atsain, A., Nyangito, H., Padilla, M., Ghersi, G. and Le Vallée, J. 2004 Development strategies and food and nutrition security in Africa: an assessment. 2020 Discussion Paper No. 38. http://www.energia.org/biofuelscasestudies. html (17 February 2010).

Henning, R.K. 2006 Jatropha curcas in Africa: an evaluation global facilitation unit for underutilised species. http://www. underutilizedspecies.org/Documents/ PUBLICATIONS/ Jatropha_curcas_africa.pdf (5 January 2009).

International Assessment of Agricultural Knowledge, Science and Technology for Development (IAASTD) 2008a Bioenergy and biofuels: opportunities and constraints. Issues in Brief, Island Press. http://www.agassessment.org/ docs/10505_Bioenergy.pdf (19 May 2011).

International Assessment of Agricultural Knowledge, Science and Technology for Development (IAASTD) 2008b Towards Multifunctional Agriculture for Social, Environmental and Economic Sustainability. Issues in Brief, Island Press. http://www.agassessment.org/docs/10505_ Multi.pdf (19 May 2011).
International Fund for Agricultural Development (IFAD) 2011 Rural poverty report 2011. IFAD, Rome.

IISD/UNIDO 2007 First High-Level Biofuels Seminar in Africa Bulletin: A Summary Report. 30 July - 1 August 2007. Addis Ababa, Ethiopia. http://www.unido.org/fileadmin/user_media/ Services/Energy_and_Climate_Change/ Renewable_Energy/Conference_Ethiopia/IISD_ coverage.pdf (21 March 2011).

International Risk Governance Council (IRGC) 2008 Risk governance guidelines for bioenergy policies, Policy Brief of the IRGC. Geneva, Switzerland.

International Sugar Organization (ISO) 2008 Sugarcane smallholders in sub-Saharan Africa: status, challenges, and strategies for development. ISO, London.

IUCN 2009 Guidelines on biofuels and invasive species. IUCN, Gland, Switzerland. http://data. iucn.org/dbtw-wpd/edocs/2009-057.pdf. (27 September 2010).

Johnson, F.X. and Matsika, E. 2006 Bio-energy trade and regional development: the case study of bio-ethanol in southern Africa. Energy for Sustainable Development 10(1): March.

Karekezi, S. and Majoro, L. 2002 Improving modern energy services for Africa s urban poor. Energy Policy Journal Special Issue 30(11-12): 1015-1028.

Karlsson, G. and Banda, K. 2009 Biofuels for sustainable rural development and empowerment of women: case studies from Africa and Asia. http://www.energia.org/ biofuelscasestudies.html (17 February 2010).

Kemp-Benedict, E. 2011 The National Bioenergy Investment Model NBIM. Technical Documentation. Stockholm Environment Institute Working Paper. SEI, Stockholm, Sweden.

Kibwage, J.K., Odondo A.J. and Momanyi, G.M. 2009 Assessment of livelihood assets and strategies among tobacco and non tobacco growing households in south Nyanza region, Kenya. African Journal of Agricultural Research 4(4): 294-304.

Koh, L.P. and Ghazoul, J. 2008 Biofuels, biodiversity, and people: understanding the conflicts and finding the opportunities. Biological Conservation 141: 2450-2460 
Koh, L.P. and Wilcove, D.S. 2008 Is oil palm agriculture really destroying tropical biodiversity? Conservation Letters 1-5: 1-14.

Koizumi, T. 2005 The Brazilian ethanol programme: impacts on world ethanol and sugar markets. International Sugar 107(1275): 166-77.

Lerner, A., Matupa, O., Mothlathledi F., Stiles, G. and Brown, R. 2010 SADC Biofuel state of play. SADC.

Lotze-Campen, H., Popp, A., Beringer, T., Muller, C., Bondeau, A., Rost, S. and Lucht, W. 2009 Scenarios of global bioenergy production: the trade-offs between agricultural expansion, intensification and trade. Ecological Modelling 221(18): 2188-96.

Matavel, D.R. 2009 Jatropha! A socio-economic pitfall for Mozambique. SwissAid. www.swissaid.ch/ global/PDF/entwicklungspolitik/agrotreibstoffe/ Report_jatropha_JA_and_UNAC.pdf (4 June 2010).

Mayers, J., Evans, J. and Foy, T. 2001 Raising the stakes: impacts of privatisation, certification and partnerships in South African forestry. International Institute for Environment and Development, London.

McIndoe-Calder, T. 2011 Network effects and land redistribution: a natural experiment in Zimbabwe. Department of Economics, Trinity College, Dublin, Ireland. http://www.csae. ox.ac.uk/conferences/2011-EdiA/papers/271McIndoeCalder.pdf (20 March 2011).

Mengesha, F. 2011 Gaia lessons and modifications of ethanol production: small-scale vs. large-scale approaches. ETHOS Conference. 28-30 January. http://www.scribd.com/doc/47727851/GaiaLessons-Modifications-to-Ethanol-ProductionSmall-Scale-vs-Large-Scale (20 March 2011).

Miranda, R.C., Sepp, S., Ceccon, E., Mann, S. and Singh, B. 2010 Sustainable production of commercial woodfuel: lessons and guidance from two strategies. The energy sector management assistance program. World Bank, Washington, DC.

Mohamed, F.A. 2007 Sustainable biofuel production and use with a focus on Africa. Eastern and Southern Africa regional workshop on biofuelsUNEP, Nairobi, Kenya, 28-29 June. http://www. unep.org/urban environment/PDFs/Fatin.pdf (24 July 2008).

Moraes, M.A.F.D. 2007 Indicadores do mercado de trabalho do sistema agroindustrial da cana-de- açúcar do Brasil no período 1992-2005. Estudos Econômicos 37(4) Oct.-Dec.

Mugo, F. and Ong, C. 2006 Lessons of eastern Africa's unsustainable charcoal trade. ICRAF Working Paper no. 20. World Agroforestry Centre, Nairobi, Kenya.

Ngepah N. 2010 Socio-economic Impacts of biofuels: methodologies and case study examples. In: Amezaga, J. M., von Maltitz, G.P. and Boyes, S.L. (eds) Projects in developing countries a framework for policy evaluation. Newcastle University, Newcastle on Tyne, UK.

Nhantumbo, I. and Salomão, A. 2010 Biofuels, land access and rural livelihoods in Mozambique, International Institute for Environement and Development, London.

Nisiku, N. and Botha, W. 2007 Tobacco revenue management: Malawi case study. International Institute for Sustainable Development, Winnipeg, Manitoba, Canada.

Nnanna, G. 2010 Addressing the food versus fuel debate in Ghana. http://www.theghanaianjournal. com/2010/02/08/addressing-the-foodversus-fueldebate-in-ghana/ (26 February 2010).

Oakland Institute 2009 The great land grab: rush for the world's farmland threatens food security for the poor. www.oaklandinstitute.org/pdfs/ LandGrab_final_web.pdf. (28 February 2011).

Openshaw, K. 2000 A review of Jatropha curcas: an oil plant of unfulfilled promise. Biomass Bioenergy 2000 19: 1-15.

Pahariya, N.C. and Mukherjee, C. 2007 Commodity revenue management: India's rapeseed/mustard oil sector. International Institute for Sustainable Development. http://www.iisd.org/pdf/2007/ trade_price_case_rapeseed.pdf. (15 March 2011),

Pimentel, D., Marklein, M., Toth, M.A., Karpoff, M.N., Paul, G.S., McCormack, R., Kyriazis, J. and Kruger, T. 2010 Why we should not be using biofuels - environmental and economic costs. In: Rosillo-Calle, F. and Johnson, F.X. (eds) Food versus fuel. Zed Books, London and New York.

Porter, G. and Phillips-Howard K. 1997 Comparing contracts: an evaluation of contract farming schemes in Africa. World Development 25(2): 227-238.

Practical Action Consulting 2009 Small-scale bioenergy initiatives: brief description and preliminary lessons on livelihood impacts from 
case studies in Asia, Latin America and Africa. FAO, Rome.

Rainer, J. and Rutz, D. 2009 COMPETE: third periodic activity report. ANNEX 6-3-2: Policy Recommendation Paper. Competence Platform on Energy Crop and Agroforestry Systems for Arid and Semi-arid Ecosystems - Africa. http:// www.compete-bioafrica.net/policy/Annex6-32-COMPETE-032448-3rdReport2009-D6.3WIP-PolicyRecommendationPaper-Final.pdf (21 January 2011).

Rajagopal, D. 2007 Rethinking current strategies for biofuel production in India. Presented at International Water Management Institute Conference, Hyderabad, India, 29-30 January. http://www.lk.iwmi.org/EWMA/files/papers/ rajagopal_biofuels_final_Mar02.pdf. (19 May 2010).

Richardson, B. 2010 Big Sugar in southern Africa: rural development and the perverted potential of sugar/ethanol exports. Journal of Peasant Studies 37(4): 917-938.

Rosegrant, M.W., Cline, S.A., Li, W., Sulser, T.B. and Valmonte-Santos, R.A. 2005 Looking ahead: long-term prospects for Africa's agricultural development and food security. 2020 Discussion Paper 41 International Food Policy Research Institute, Washington, DC.

Rosegrant, M.W. 2008 Biofuels and grain prices: impacts and policy responses. International Food Policy Research Institute, Washington DC.

Rosillo-Calle, F. and Cortez, L.A.B. 1998 Towards ProAlcool II - a review of the Brazilian bioethanol programme. Biomass Bioenergy 14(2): 115-24.

Rossi, A. and Lambrou, Y. 2009 Making sustainable biofuels work for smallholder farmers and rural households: issues and perspectives. FAO, Rome. http://www.fao.org/docrep/012/ i0891e/i0891e00. htm (22 September 2010).

Rudel, T.K., Schneider, L., Uriarte, M., Turner II, B.L., DeFries, R., Lawrence, D., Geoghegan, J., Hecht, S., Ickowitz, A., Lambin, E.F. et al. 2009 Agricultural intensification and changes in cultivated areas, 1970-2005. Proceedings of the National Academy of Sciences, USA 106: 20675-20680.

SADC 2010 SADC framework for sustainable biofuel use and production. Approved by SADC biofuel taskforce on 10 December 2009. Approved by SADC Energy Ministers Meeting on 29 April
2010. http://www.probec.org/fileuploads/ fl06022010194145_SADC_framework_for_ sustainable_biofuels_2010.pdf (25 January 2010).

Sala, O.E., Sax, D. and Leslie, L. 2009 Biodiversity consequences of increased biofuel production. In: Howarth, R.W. and Bringezu, S. (eds) Biofuels: environmental consequences and interactions with changing land use. Report of the International SCOPE Biofuels Project. http:// cip.cornell.edu/biofuels/ (20 March 2011).

Scania 2007 Scania's latest and cleanest ethanol buses have their world première in Stockholm traffic. http://www.scania.com/media/pressreleases/ n07061en.aspx (17 December 2010).

Schlag, N. and Zuzarte, F. 2008 Market barriers to clean cooking fuels in sub-Saharan Africa: literature review. SEI Working Paper. Stockholm Environmental Institute, Stockholm, Sweden.

Schoneveld, G.C., German, L. and Nutakor, E. 2010 Biofuel feedstock production in Ghana: a case analysis of environmental and socioeconomic impacts. Report prepared as part of the European Community Contribution Agreement EuropeAid/ENV/2007/143936/TPS. CIFOR, Bogor, Indonesia.

Schut, M., Slingerland, M. and Locke, A. 2010 Biofuel developments in Mozambique. Update and analysis of policy, potential and reality. Energy Policy 38: 5151-5165.

Schutter O.D. 2009 Large-scale land acquisitions and leases: a set of core principles and measures to address the human rights challenge. www2.ohchr. org/english/issues/food/.../ BriefingNotelandgrab. pdf (3 March 2011).

Sepp, S. 2008 Analysis of charcoal value chains - general considerations. Gesellschaft für Internationale Zusammenarbeit. http://www. hedon.info/docs/charcoal-supply-chains.pdf (28 July 2010).

Shackleton, S.E. and Gumbo, D. 2010 Contribution of non-wood forest products to livelihoods and poverty alleviation. In: Chidumayo, E.N. and Gumbo, D.J. (eds) The dry forests and woodlands of Africa: managing for products and services, $\mathrm{p}$. 63-92. Earthscan, London.

Shackleton, S.E., Cocks, M., Dold, A., Kaschula, S., Kokwe, G., Mbata, K. and von Maltitz, G. 2010 Non-wood forest products: description, use and management. In: Chidumayo, E.N. and Gumbo, D.J. (eds) The dry forests and woodlands of 
Africa: managing the forests for products and services, p.93-130. Earthscan, London.

Silversands 2010 http://www.silversandsethanol.co.za/ literature.html (5 November 2010).

Singh, K.J. and Sooch, S.S. 2004 Comparative study of economics of different models of family size biogas plants for state of Punjab, India. Energy Conversion and Management 2004 45: 1329-41.

Simmons, P. 2002 Overview of smallholder contract farming in developing countries. FAO Working Paper ESA/02-04. Food and Agriculture Organization of the United Nations, Rome.

Sinkala, T. 2008 Liquid biofuels as a viable alternative to fossil fuels. Working paper prepared for the Global Renewable Energy Forum. Foz do Iguancu, Brazil, 18-21 May.

Smeets, E.M.W. 2008 Possibilities and limitation for sustainable bioenergy production systems. $\mathrm{PhD}$ dissertation, University of Utrecht. Utrecht, Netherlands.

Smeets, E.M.W., Faaij, A.P.C., Lewandowski, I.M. and Turkenburg, W.C. 2007 A bottom-up assessment and review of global bio-energy potentials to 2050. Progress in Energy and Combustion Science 33(1): 56-106.

Sulle, E. and Nelson, F. 2009 Biofuels, land access and rural livelihoods in Tanzania. International Institute for Environment and Development, London. www.iied.org/pubs/ pdfs/12560IIED.pdf (21 March 2011).

Royal Society 2008 Sustainable biofuels: prospects and challenges. Policy document 01/08. Royal Society, London.

Takane, T. 2004 Smallholders and nontraditional exports under economic liberalization: the case of pineapples in Ghana. African Study Monographs 25(1): 29-43.

Tigere, T.A., Gatsi, T.C., Mudita, I.I., Chikuvire, T.J., Thamangani S. and Mavunganidze Z. 2006 Potential of Jatropha curcas in improving smallholder famers livelihoods in Zimbabwe: an exploratory study of Makosa Ward, Mutoko District. Journal of Sustainable Development in Africa 8: 1-9.

UNIDO 2009 UNIDO's biofuel strategy. http://www. unido.org/fileadmin/import/68441_final_draft_ unido_biofuel_strategy.pdf (21 March 2011).

United Nations Department of Economic and Social Affairs (UNDESA) 2007 Small-scale production and use of liquid biofuels in sub-Saharan Africa: perspectives for sustainable development.

Background Paper No. 2 DESA/DSD/2007/2.

http://www.un.org/esa/sustdev/csd/csd15/

documents/csd15_bp2.pdf (12 December 2010)

United Nations Development Programme (UNDP) 2005 A guide to energy's role in reducing poverty. UNDP, New York.

United Nations Economic and Social Council (UNESC) 2007 Africa review report on agriculture and rural development (summary). Economic commission for Africa. Fifth meeting, African Committee on Sustainable Development. Addis Ababa, Ethiopia. http://www.uneca.org/ csd/csd5/ACSD-5ReportAgricultureSummary. pdf accessed 6 Jan 2011 (17 December 2010).

Van Eijck, J., Smeets, E., Romijn, H., Balkema, A. and Jongschaap, R. 2010 Jatropha assessment: agronomy, socio-economic issues, and ecology. NL Agency. Ministry of Economic Affairs, Agriculture and Innovation, Netherlands.

Valentino, S. 2011Tanzania’s biofuel project's promise proves barren. Mail and Guardian Today http:// mg.co.za/article/2011-03-10-tanzanias-biofuelprojects-promise-proves-barren (10 March 2011).

Vermeulen, S. and Cotula, L. 2010 Over the heads of local people: consultation, consent, and recompense in large-scale land deals for biofuels projects in Africa. Journal of Peasant Studies 37(4): 899-916.

Vermeulen, S. and Goad, N. 2006 Towards better practice in smallholder palm oil production, International Institute for Environment and Development, London. http://www.rspo.org/ PDF/Projects/STF/final\%20IIED\%20report\%20 on\%20smallholder\%20palm\%20oil.pdf (20 October 2009).

Vermeulen, S., Sulle, E. and Fauveaud, S. 2009 Biofuels in Africa: growing small-scale opportunities. IIED briefing. International Institute for Environment and Development, London. www. iied.org/pubs/display.php?o=17059IIED (21 March 2011).

Vis, M.W., Vos, J. and van den Berg, D. 2008 Sustainability criteria and certification systems for biomass production. A report prepared for DG TREN - European Commission, Project 1386. Biomass Technology Group, Enschede, Netherlands.

von Braun, J. and Meinzen-Dick, R. 2009 Land grabbing by foreign investors in developing countries: risks and opportunities. IFPRI Policy 
Brief 13, April. International Food Policy Research Institute, Washington, DC.

Von Malititz, G.P., and Brent, A. 2008. Assessing the biofuel options for Southern Africa. Science real and relevant: 2nd CSIR Biennial Conference, Pretoria, South Africa, 17-18 November, p.16. http://hdl.handle.net/10204/2579 (21 March 2011).

von Maltitz, G., German, L. and Schoneveld, G. 2010 (draft) Lessons learnt from large-scale bioenergy development: implications for forestrich countries in Africa, Asia, and Latin America Activity 4.1. Report prepared as part of the European Community Contribution Agreement EuropeAid/ENV/2007/143936/TPS.

von Maltitz, G., Haywood, L., Mapako, M. and Brent, A. 2009 Analysis of opportunities for biofuel production in sub-Saharan Africa. CIFOR, Bogor, Indonesia.

von Maltitz, G.P., Nickless, A., and Blanchard. R. 2010 Maintaining biodiversity during biofuel development. In: Amezaga J. M., von Maltitz, G.P. and Boyes, S.L. (eds) Assessing the sustainability of biofuel projects in developing countries. a framework for policy evaluation. Newcastle University, Newcastle upon Tyne, UK.

Walker, B., Holling, C.S., Carpenter S.R., Kinzig, A. 2004 Resilience, adaptability and transformability in social-ecological systems. Ecology and Society 9(2). http://www.ecologyandsociety.org/vol9/iss2/ art5 (21 March 2011).

Watson, H.K. 2010 Potential to expand sustainable bioenergy from sugarcane in southern Africa. Energy Policy 2010, doi:10.1016/j. enpol.2010.07.035.

Wiggans, S. 1009 Can the smallholder model deliver poverty reduction and food security for a rapidly growing population in Africa? FAC Working Paper No. 8, Future Agriculture Consortium, Brighton, UK.
Wijgerse, I. 2008 The electricity system for a rural village in Mali. Sustainable Energy Technology. MSc. thesis, Eindhoven University of Technology, Eindhoven, Netherlands.

Wolde-Georgis, T. and Glantz, M.H. 2009 Biofuels in Africa: a pathway to development. International Research Center for Energy and Economic Development Occasional Papers No. 43. Organisation for Economic Co-operation and Development (OECD)/ITF, Paris.

Woods, J. and Diaz-Chavez, R. 2007 The environmental certification of biofuels. International Transport Forum. Joint Transport Research Centre. Discussion paper 19.

World Bank 2009 Environmental crisis or sustainable development opportunity? Transforming the charcoal sector in Tanzania: a policy note. World Bank, Washington DC.

World Bank 2010 Raising global interest in farmlands. Can it yield sustainable and equitable benefits? World Bank, Washington, DC.

Zarrilli, S. and Burnett, J. 2008 Making certification work for sustainable development: the case for biofuel. United Nations Conference on Trade and Development. United Nations, Geneva, Switzerland.

Zulu, C. 2010 The forbidden fuel: charcoal, urban woodfuel demand and supply dynamics, community forest management and woodfuel policy in Malawi. Energy Policy 38: 3717-3730.

Zuzarte, F. 2007 Ethanol for cooking. Feasibility of small-scale ethanol supply and its demand as a cooking fuel: Tanzania case study. MSc Thesis. KTH School of Energy and Technology, Stockholm, Sweden. 

Sustainable biofuel production should provide opportunities for sub-Saharan African countries and their inhabitants, especially in impoverished rural areas. Biofuel feedstock production has the potential to bring job opportunities and earnings, but this should not be at the cost of existing livelihoods and the local environment. Biofuels also have the potential to increase energy security in these countries for both transportation and household needs.

Sub-Saharan African biofuel feedstock production projects can be classified into 4 distinct models based on production scales (small- versus large-scale farm/plantations) and on the intended use of the biofuel (local versus national). The first type embraces large corporate plantations to supply the market for liquid transport fuel blends. The second type comprises small-scale producers linked to the corporate producers. The third type involves small-scale producers supplying the local energy needs of farmers and villages. The fourth and rarest type is linked to the large corporate plantations, to meet the corporation's own energy needs.

The introduction of foreign-owned, large-scale corporate plantations producing biofuel for transport fuel blends causes the most concern in sub-Saharan Africa, as their scale and ownership arrangements may disrupt rural livelihoods and affect access rights to land resources. However, these projects can also bring job opportunities, thereby providing alternative sources of income for poor communities. This working paper assesses mechanisms for limiting the negative impacts while maximising national benefit capture. Market-based mechanisms versus legal and policy mechanisms to enhance long-term sustainability are also discussed. 